Czaja, R., Manfredi, C. and Price, J. (2003) The Determinants and Consequences of Information Seeking Among Cancer Patients. Journal of Health Communication 8(6):529-562 (Nov 2003). Published by Taylor \& Francis (ISSN: 1081-0730). DOI: 10.1080/10810730390250470

\title{
The Determinants and Consequences of Information Seeking Among Cancer Patients
}

\author{
Ronald Czaja, Clara Manfredi, and Jammie Price
}

\begin{abstract}
This research was designed to examine information seeking behavior among cancer patients. We present a model which identifies the determinants and consequences of information seeking and, in turn, examines the effects of prior variables on four outcome variables: whether patients discussed with their physicians information that they received from other sources, whether the information they obtained helped them make decisions about treatment or care, whether the patient sought a second opinion about his / her diagnosis or treatment, and changes in self-reported stress levels from diagnosis to the time of interview. The model is estimated separately for three groups: patients who sought information from multiple sources including the National Cancer Institute's Cancer Information Service, patients who sought information from multiple sources but did not call the Cancer Information Service, and patients who did not seek information other than from their physician(s). We discuss variables that have similar impacts on outcome variables in all three groups as well as variables that operate differently within the groups. The results indicate that the desire for information and the desire for involvement in medical care decisions are independent factors. Some patients have a strong desire for both information and involvement in making health care decisions. These patients actively seek involvement in their treatment plans. Other patients, however, want to be informed about their disease and treatment but prefer to delegate most decision-making to their physicians. Still other patients choose to delegate information gathering and decision making exclusively to their physicians. We discuss the implications of these results for both patients and providers.
\end{abstract}




\section{INTRODUCTION}

Over the last two decades the medical community has urged physicians to share information with their patients and has urged patients to seek medical information and participate in their medical care (Degner, 1997; Luker, Beaver, Leinster, Owens, \& Glynn, 1996; Emanuel \& Emanuel, 1992). However, many studies show that while most patients desire information, there are some that do not, and many do not actively seek to participate in their medical care (Rees and Bath, 2001; Leydon, Boulton, Moynihan, Jones, Mossman, Boudioni and McPherson, 2000; Degner, 1997; Reiser, 1993; Siminoff and Fetting, 1991; Beisecker and Beisecker, 1990; Coulton, 1990). Rather than actively seeking information and participation, many patients prefer that their physicians provide them with information about their disease and treatment and make medical decisions for them (Leydon et al., 2000; Johnson, 1997; Scott, 1991; Wiggers, Donovan, Redman, \& Sanson-Fisher, 1990).

Apparently, there are fundamental differences between those patients who say they desire information and participation in their medical care and those who actually seek information and use it to participate in their medical care (Rees \& Bath, 2000). The process through which these differences influence patients has yet to be fully explained (Johnson, 1997). In addition, most of the previous studies have been limited in their scope or generalizability. They have been conducted in university medical centers or at one research site, have used small or purposive samples of patients $(n<100)$ or physicians $(n<25)$, or have examined information seeking only within specific types of medical encounters.

In this paper, we examine the processes of information seeking and outcomes in three separate patient groups, each reflecting a different level of information-seeking interest and activity. We present a model which identifies key factors that function as determinants of information seeking and the effect of information seeking on selected outcome variables.

\section{MODEL SPECIFICATION}

The initial model that we tested is shown in Figure 1. It is a composite model based on the early work of Andersen, Aday, and colleagues (Andersen \& Anderson, 1967; Andersen, Kravits, \& Anderson, 1975; Aday \& Andersen, 1974) and Green (1974); as well as on Andersen and Aday's more recent research (Andersen, 1995; Aday \& Awe, 1997). Andersen and colleagues proposed two concepts_-predisposing and enabling-as determinants of health care utilization and influencing health education efforts. Green (1974) proposed a third-reinforcing. We incorporated these factors with some variation into our model which is similar to the Comprehensive Model of Information Seeking proposed by Johnson (1997). We hypothesized that contextual and sociodemographic variables would influence predisposing, enabling, and reinforcing factors and that these, in turn, would influence information seeking. We also investigated what variables, including information seeking, might affect four outcome variables: (1) whether patients discussed with their physicians information that they received from other sources, (2) whether the information they obtained helped them make decisions about treatment or care, (3) whether the patient sought a second opinion about their diagnosis or treatment, and (4) self-reported stress level at the time of interview. 


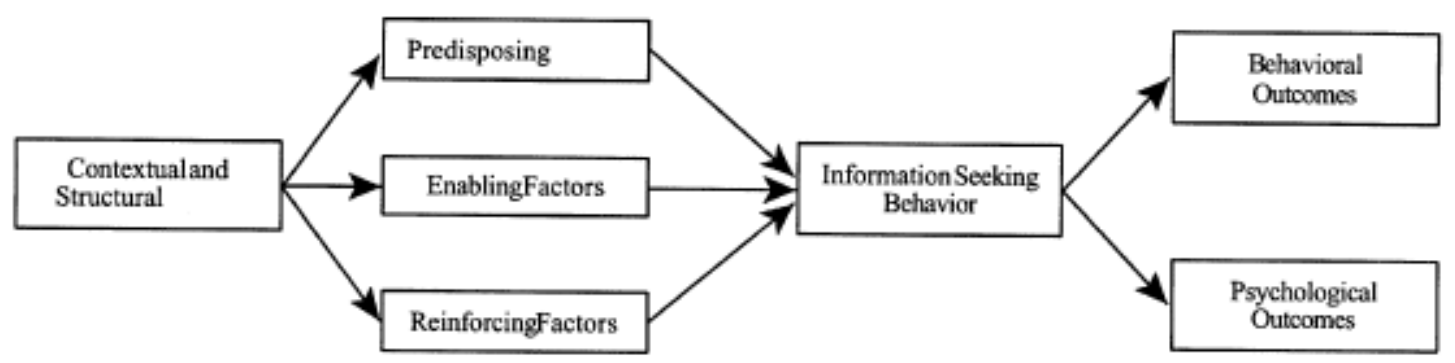

FIGURE 1 Initial conceptual model of patient information seeking.

The first part of the model includes contextual and structural variables that affect all the other components of the model. A number of studies have reported factors that influence the decision to seek or not to seek information and the desire to participate in medical decision making (Rees \& Bath, 2001; Carlsson, 2000; Leydon et al., 2000; Degner, 1997: Lavery \& Clarke, 1996; Hughes, 1993; Johnson \& Meischke, 1993a). Demographic characteristics such as younger age, female gender, higher socioeconomic status, and being married are all positive determinants of information seeking (Carlsson, 2000; Nair, Hickok, Roscoe, \& Morrow, 2000; van der Molen, 1999; Muha, Smith, Baum, Ter Maat, \& Ward, 1998; Woolf \& Dickens, 1995; Manfredi, Czaja, Buis, \& Derk, 1993; Siminoff \& Fetting, 1991). Those least likely to seek information have been the elderly and there have been mixed results concerning the effects of prior knowledge. A recent review of the literature by Mills and Sullivan (1999) has identified a number of disease-related factors that have been found to predict information needs and activity. These include time since diagnosis, type of cancer, type of treatment, and stage of disease. For example, the time since diagnosis may influence the type of information needed and where and how intensely the information is sought (Mills \& Sullivan, 1999; Luker et al., 1996). Other contextual characteristics of those most likely to seek information are concern about getting cancer and having a family member or personal friend treated for cancer (Johnson, Meischke, Grau, \& Johnson, 1992).

Contextual factors related to the patient's medical care situation can have either a positive or negative effect on information seeking or the outcome variables. For example, having a cooperative and supportive physician, disruptiveness of treatment, seriousness of illness, specialty of the diagnosing physician, hospital type and bed size, and number of hospitals visited have been shown to influence both information seeking and psychological and behavioral outcome variables (Johnson, 1997; Beisecker \& Beisecker, 1990; Coulton, 1990; Larsson, Svardsudd, Wedel, \& Saljo, 1989; Derdiarian, 1989). Since physician specialties and hospital resources are highly associated with population size, the patient's county of residence can also be an important structural variable. The further patients must travel to receive specialized care or resources, the less likely they are to do so, all things being equal.

There is mixed evidence about the effect of anxiety on information seeking. High anxiety due to one's cancer diagnosis was found to be associated with less information seeking in one study (Wilkinson \& Wilson, 1983) and more information seeking in another study (Manfredi, Czaja, Price, Buis, \& Janiszweski, 1993) while a third study found that lack of information can lead to anxiety and coping problems (van der Molen, 1999). 
Predisposing factors include beliefs and attitudes which enhance the likelihood that individuals will want to seek information and medical participation. A desire to actively participate in treatment decisions (Degner, 1997) and to have a clear understanding of the extent to which one's cancer has progressed and the prognosis for survival (Luker et al., 1996; Rees \& Bath, 2001) were found to motivate information seeking. These variables may reflect an internal locus of control that was also found to predict information seeking (Shapiro, Najman, Chang, Keeping, Morrison, \& Western, 1983). On the other hand, some patients may be predisposed to avoid information so as not to challenge their faith in their treating physicians and their hope of cure and survival (Leydon et al., 2000).

Enabling factors represent the resources that facilitate patients' access to and use of services. Here, we include social network variables and variables measuring familiarity with the medical system, cancer, and cancer treatment. Several studies show that knowledge about cancer and treatment and familiarity with the medical system encourage patient information seeking (Leydon et al., 2000; Turk-Charles, Meyerowitz, \& Gatz, 1997; Meischke \& Johnson, 1995; Hughes, 1993), as does emotional and social support from family and friends (Echlin \& Rees, 2002; Elf \& Wikblad, 2001; Thoits, 1995; Johnson \& Meischke, 1993b; Coulton, 1990), and presence of a companion during physician visits (Beisecker \& Beisecker, 1990; Buller \& Buller, 1987). Another study, however, found that those who had prior knowledge due to a relevant prior experience were least likely to seek information (Wilkinson \& Wilson, 1983).

Reinforcing factors include both the encouragement and the disincentives that patients receive from health professionals or others for engaging in certain behaviors. Several studies report the positive effects of various reinforcing factors on information seeking. Siminoff and Fetting (1991) documented the importance of amount, specificity, and clarity of information given by physicians. Other studies have shown that patient comfort in asking questions (Derdiarian, 1989), clear physician answers (Rees \& Bath, 2000; Lerman et al., 1990), and a positive physician reaction to patient question asking (Shye, Javetz, \& Shuval, 1990) lead to further patient information seeking.

Our model holds that seeking information from a variety of sources leads to positive behavioral and psychological outcomes (Mills \& Sullivan, 1999; Johnson, 1997). The benefits of seeking information and using it to participate in medical decision making include (a) improved discussions and satisfaction between patients and their treating physicians (Rees \& Bath, 2001), (b) empowering patients to exercise their freedom of self determination (Davison \& Degner, 1997; Lewis, Pearson, Corcoran-Perry, \& Narayan, 1997), (c) better coping with threatening events and adjustment to illness (Rees \& Bath, 2001; Derdiarian, 1989; Ende, Kazis, Ash, \& Moskowitz, 1989), (d) reduced anxiety and fear about illness (van der Molen, 1999), (e) increased likelihood of obtaining a second opinion and motivation to make clinical decisions (Pennbridge, Moya, \& Rodrigues, 1999), and (f) better physical and role functioning (Lerman, Brody, Caputo, Smith, Lazaro, \& Wolfson, 1990). 


\section{METHODS}

\section{SAMPLE DESIGN AND DATA COLLECTION}

Our basic research questions were what proportion of patients seek information about their cancer and possible treatments, where do they go for information, how do they use this information, and what are the outcomes of information seeking. To answer these questions, two samples of cancer patients were selected for this case-control study (Manfredi, Czaja, Buis et al. 1993; Manfredi, Czaja, Price et al. 1993). Both samples included patients or close relatives of patients diagnosed with cancer of the breast, colon, lung, or prostate or lymphoma (Hodgkin's or non-Hodgkin's) within the preceding three years. The first sample, referred to as the Cancer Information Service (CIS) sample, includes patients or relatives who called the Illinois CIS and obtained specific types of treatment-related information. This sample represents a group of cancer patients who sought and received state-of-the-art treatment information and/or a referral to a cancer specialist. The second sample, a matched control sample, was selected from the Illinois State Cancer Registry and tumor registries maintained by Illinois hospitals. This sample consists of cancer patients whose information needs and information seeking activity were intended to represent cancer patients in general. The two samples were matched, in the aggregate, on patient characteristics (gender, cancer site, median age by cancer site, and time elapsed since diagnosis) and on characteristics of the hospital where the patient was diagnosed or treated (geographic location, number of beds, and whether or not it was affiliated with a medical school and/or had a cancer program approved by the American College of Surgeons).

During the 13-month sample recruitment period, 354 patients and relatives who called the CIS were eligible for the CIS sample. Completed interviews were obtained with $257(73 \%)$ of these respondents; $114(44 \%)$ of these interviews were conducted with relatives (mostly spouses and adult children). By design, the CIS sample includes approximately equal numbers of patients with cancer of the breast (68), colon (62), lung (68), and prostate/lymphoma (59).

Selecting the control sample required a two-step process in which first, hospitals, and then the physicians of the sampled patients were asked to participate in the study. Sixtyfour (58\%) of the 111 Illinois hospitals we contacted agreed to participate; of these, 55 were able to provide cases that met the matching criteria. In the second step, 249 (68\%) of the 365 physicians we contacted gave us permission to contact their patients. In the end, we obtained permission to contact 306 eligible patients; interviews were completed for $262(86 \%)$ of these patients. Twenty-four (9\%) of these interviews were conducted with relatives.

The two samples differ in the proportion of respondents who were relatives of cancer patients. A significant proportion of the treatment related CIS calls came from relatives. To exclude these calls from the study would have resulted in an incomplete picture of the patterns through which cancer patients receive information. The identification of patients from the tumor registry led to a sample of primarily cancer patients. To ensure that relatives (e.g., spouses and adult children) in both samples were knowledgeable and actively involved with the patient, a short screening interview was conducted with each relative to determine his or her eligibility. Relatives were interviewed for cancer patients only if the relative usually accompanied the patient on medical care visits and reported 
that he or she was "very involved" in making medical care decisions with the patient and in dealing with the patient's illness.

\section{PRELIMINARY ANALYSES}

Early analyses indicated that the control sample was comprised of nearly equal numbers of respondents who had and had not sought information from sources other than their physicians. These two groups also differed on many of the other variables that we examined (we discuss these differences in the Results section). Therefore, we divided the control sample into two subgroups referred to as Control Information ( $n^{1 / 4138)}$ and

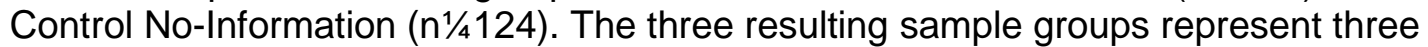
levels of information seeking: high (CIS), medium (Control Information), and low (Control No-Information). We assumed that different variables would be found to be important within groups and that the patterns of information seeking would differ across groups. Thus, we analyzed the three groups separately. This simplifies both the analysis and interpretation.

In our preliminary analyses of the model (Figure 1), we included the following variables:

\section{Contextual and Structural}

Patient's demographic characteristics-education, age, sex, marital status, urbanrural residence, employment; disease-related variables-type of cancer, whether it was a first cancer diagnosis, stress at the time of diagnosis, the disruptiveness of the treatment in the patient's life; health care related variables-type of health insurance, number of physicians seen, specialty of the diagnosing physician, number of hospitals visited, hospital bed size.

\section{Predisposing}

Patient's preferences for involvement in medical decisions and patient's need for information (see Appendix A).

\section{Enabling}

Previous medical knowledge from relatives' or friends' serious illnesses; familiarity with the health care industry from employment of self, relatives, or friends; friends and relatives to talk with about illness or helped to cope emotionally; whether a relative or friend accompanied the patient while visiting the physician; and who asked the most questions during physician visits.

\section{Reinforcing}

Whether the patient asked the physician questions, physician reaction to the patient asking questions about information obtained elsewhere, patient comfort in asking the 
physician questions, clarity of physician responses to patient questions, and patient satisfaction with the physician's answers.

\section{Information Seeking}

Number of outside sources contacted excluding the Cancer Information Service.

\section{Outcomes}

Whether the patient discussed information obtained from outside sources with his or her physician, whether the patient or physician found the information useful in clinical decision making, whether the patient sought a second opinion, and patient's change in stress since diagnosis.

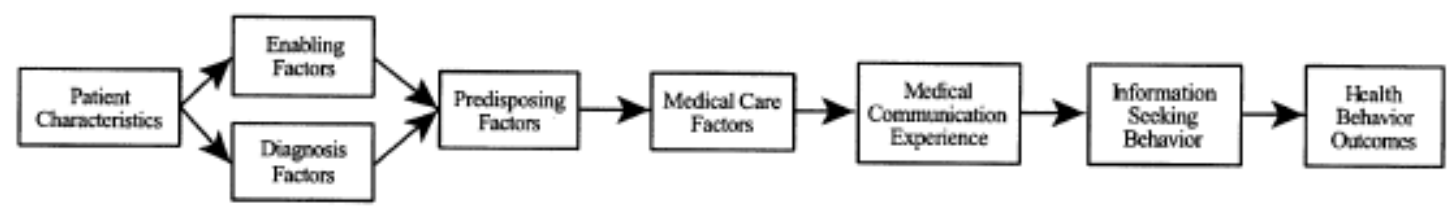

FIGURE 2 Final conceptual model of patient information seeking.

After using path analysis and ordinary least squares to estimate this model, we found inconsistent and unexpected effects from the contextual and reinforcing factors. While trying to explain these effects, we realized that these factors included characteristics that influence patient information seeking in different ways and at different times. Hence, we began reconceptualizing the model. Specifically, we questioned the meaning and causal importance of each factor; the temporal order of each factor; the rationale for the variables composing each factor; and whether each factor reflected a concept with one dimension, one concept with multiple dimensions, or multiple concepts with multiple dimensions. Figure 2 depicts the final model that we tested for each group. The statistically significant variables for each group are shown in Figures 3-5. 


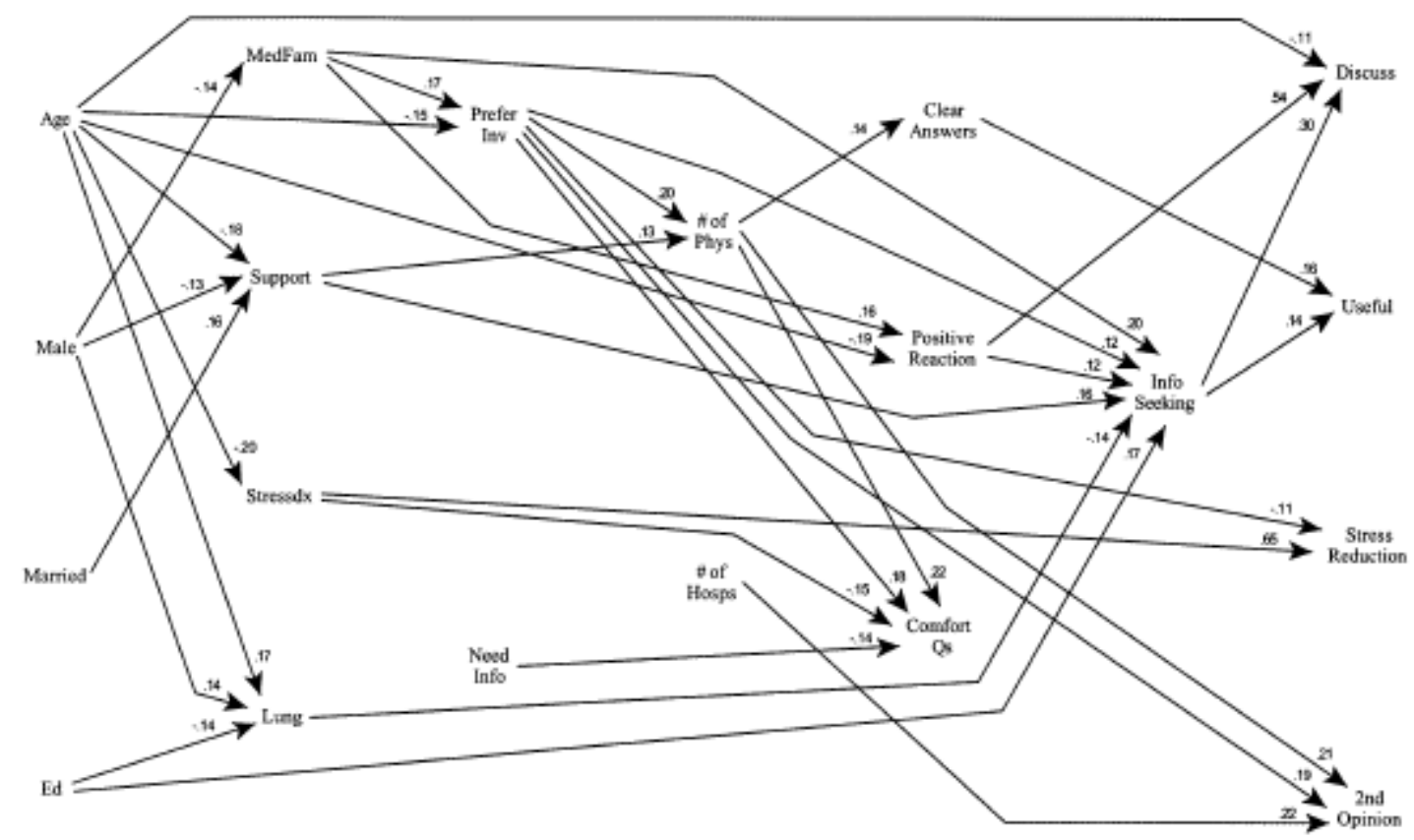

FIGURE 3 Model of significant effects of health characteristics and beliefs on information seeking and health outcomes, CIS group. Paths are standardized coefficients; $n=253$; Chi square $=98.48, \mathrm{df}=17, p<.01 ; \mathrm{AGFI}=.56 ; \mathrm{CFI}=.88$.

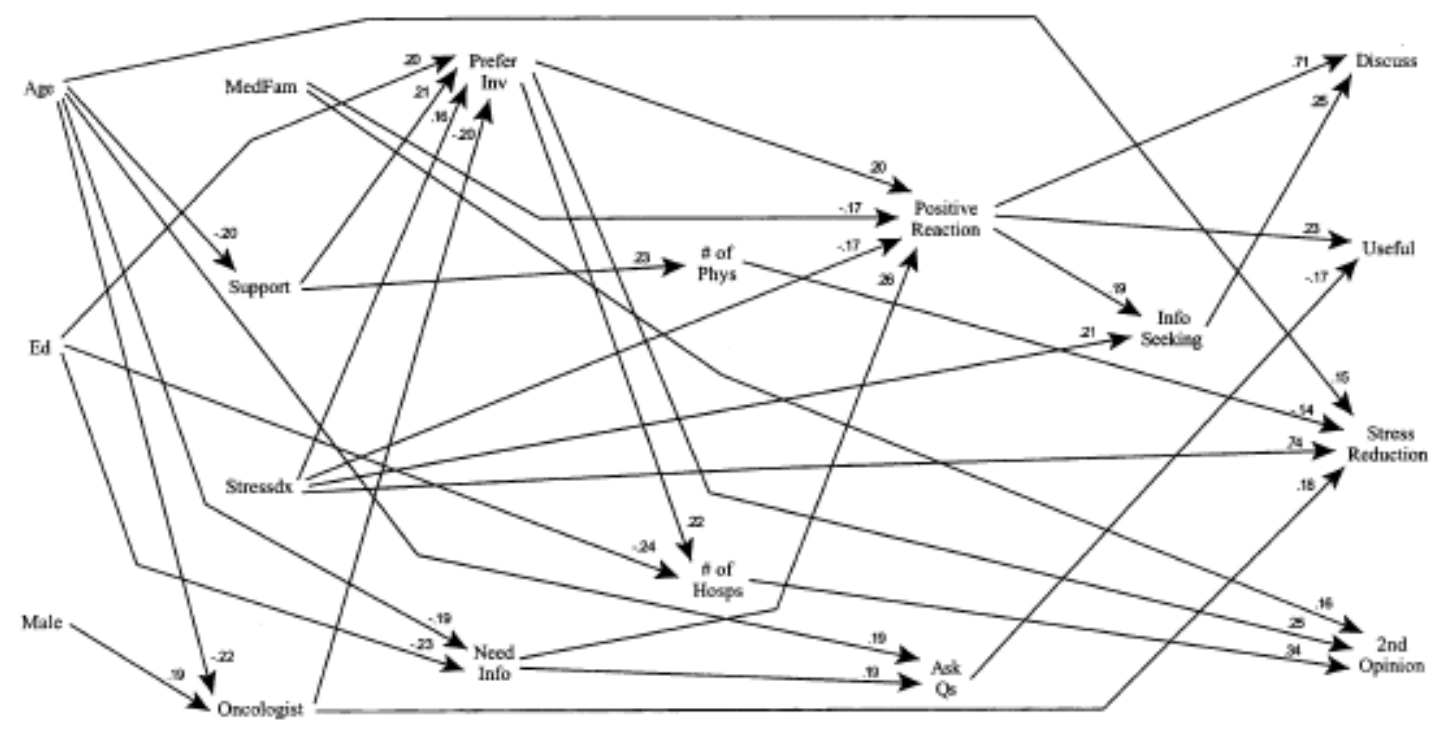

FIGURE 4 Model of significant effects of health characteristics and beliefs on information seeking and health outcomes, Control Information group. Paths are standardized coefficients; $n=136$; Chi square $=23.19, \mathrm{df}=15, p=.08 ; \mathrm{AGFI}=.78 ; \mathrm{CFI}=.98$. 


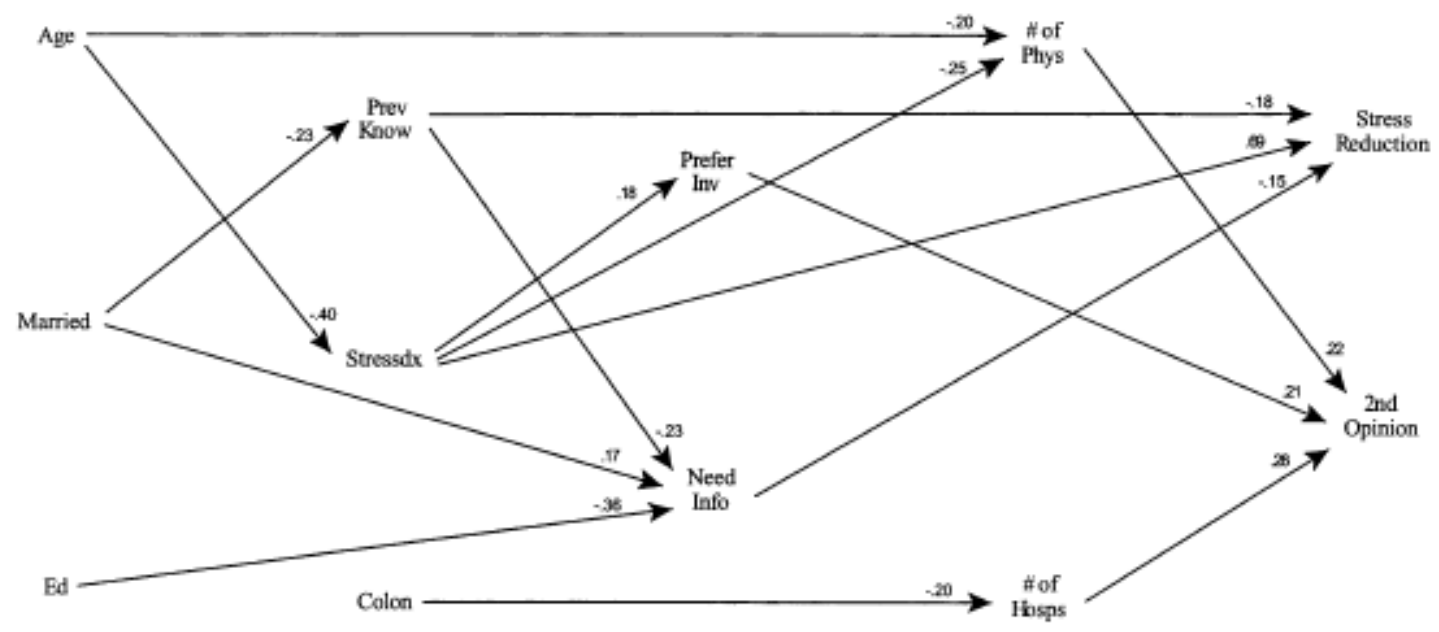

FIGURE 5 Model of significant effects of health characteristics and beliefs on health outcomes, Control No-Information group. Paths are standardized coefficients; $n=124$; Chi square $=49.45, \mathrm{df}=9, p<.01 ; \mathrm{AGFI}=.41 ; \mathrm{CFI}=.83$.

\section{Final Measures}

We made several changes to the initial model based on the preliminary analyses for each sample group. Table 1 presents definitions and descriptive statistics for each variable used in the final model. First, we partitioned the contextual and structural factor into three new factors. The new factors are: (1) "patient characteristics," representing patient's age, education, sex, and marital status; (2) "diagnosis," representing the type of cancer, stress level at diagnosis, and the specialty of the diagnosing physician; and (3) "medical care," representing the number of physicians seen and the number of hospitals visited. Second, we found that the following variables contributed nothing to the model and were dropped from further analyses: urban-rural residence, employment, type of health insurance, whether it was a first or second cancer diagnosis, self-reported disruptiveness of the treatment in the patient's life, hospital bed size, whether a relative or friend accompanied the patient while visiting the physician, who asked the most questions, and patient satisfaction with the physician's answers.

Third, we left the significant enabling and predisposing variables as is. Finally, we changed the name of the reinforcing factor to "medical communication experience." This factor includes whether patients asked questions of treating physicians, patients' degree of comfort in asking questions, clarity of physicians' answers, and whether the physician gave no negative response or reaction when the patient brought up information received from other sources.

From the preliminary analyses we hypothesized that a) patient characteristics predated and could influence enabling and diagnosis characteristics; b) the diagnosis and enabling characteristics occur simultaneously and are not likely to influence each other but could influence a patient's predisposing characteristics; c) a patient's predisposing 
characteristics could influence the number of physicians seen and hospitals visited; and d) physicians seen and hospitals visited could influence the medical communication that occurs between a patient and a physician.

The initial analyses indicated that different variables were important to the information seeking process for different groups. For the CIS group, previous knowledge, colon cancer, oncologist, and asking questions of physicians had no influence and were therefore omitted from the analysis. For the same reason, previous knowledge, colon and lung cancer, clarity of physician answers, and comfort asking questions were omitted from the Control Information model. Similarly, sex, medical familiarity, lung cancer, and oncologist were dropped for the Control No-Information group. Because of insufficient variation, the medical communication experience variables were omitted from the model for this group. In addition, information seeking, patient-physician discussion of information obtained, and usefulness of obtained information in clinical decisions were not applicable to the Control No-Information group. 


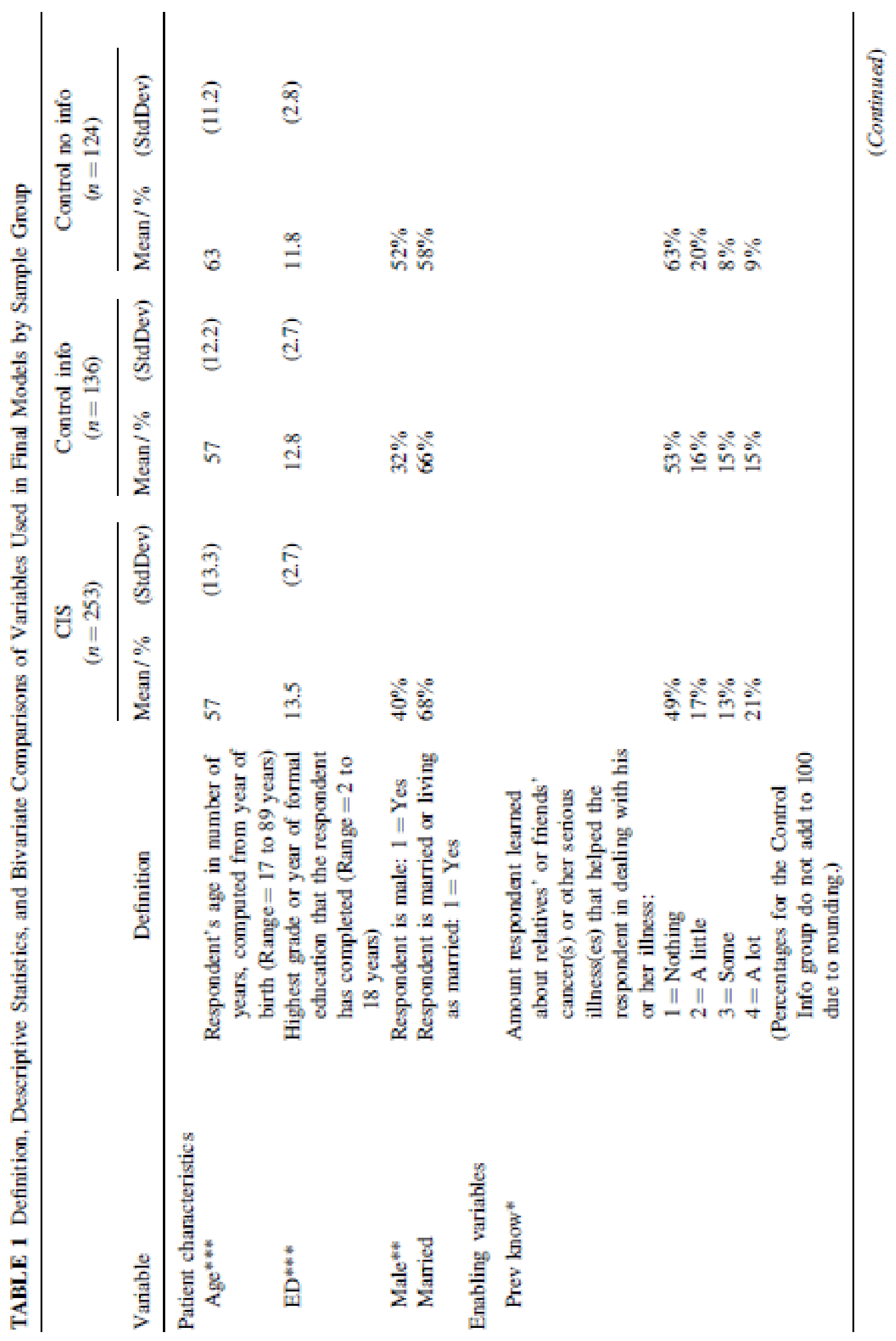




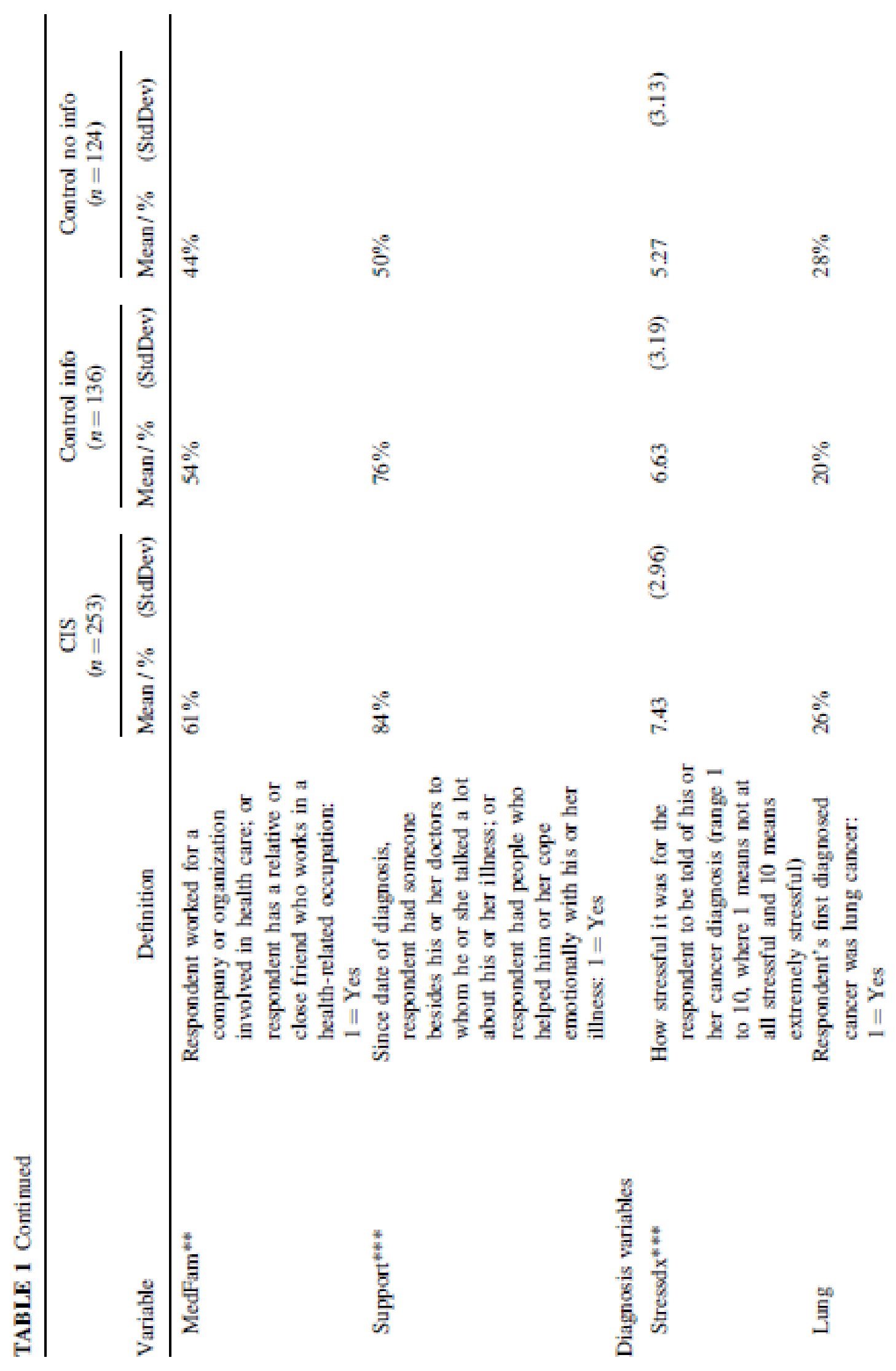



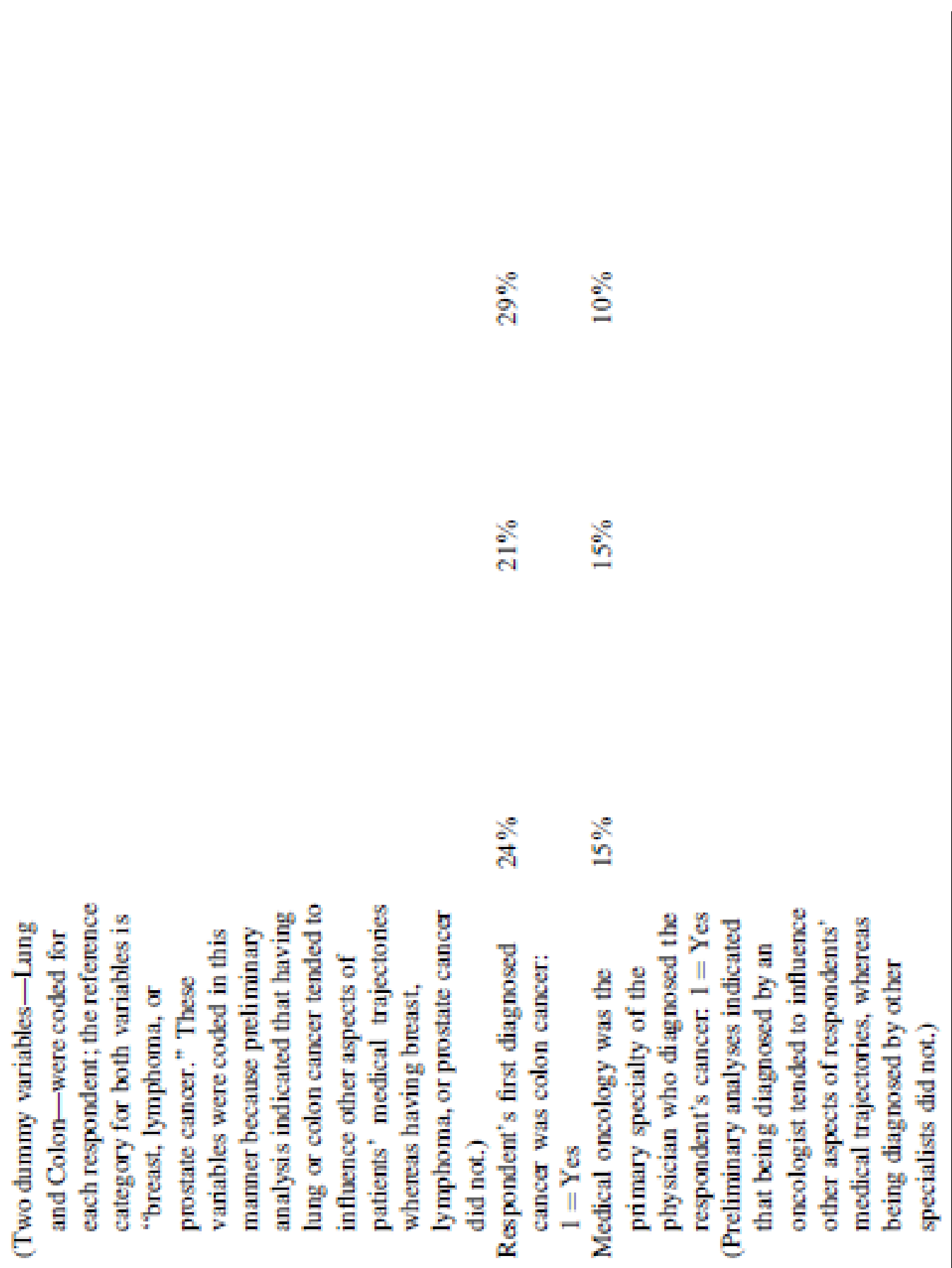

$\begin{array}{ll} & \\ \frac{5}{6} \\ 0 \\ 0 \\ 0\end{array}$ 


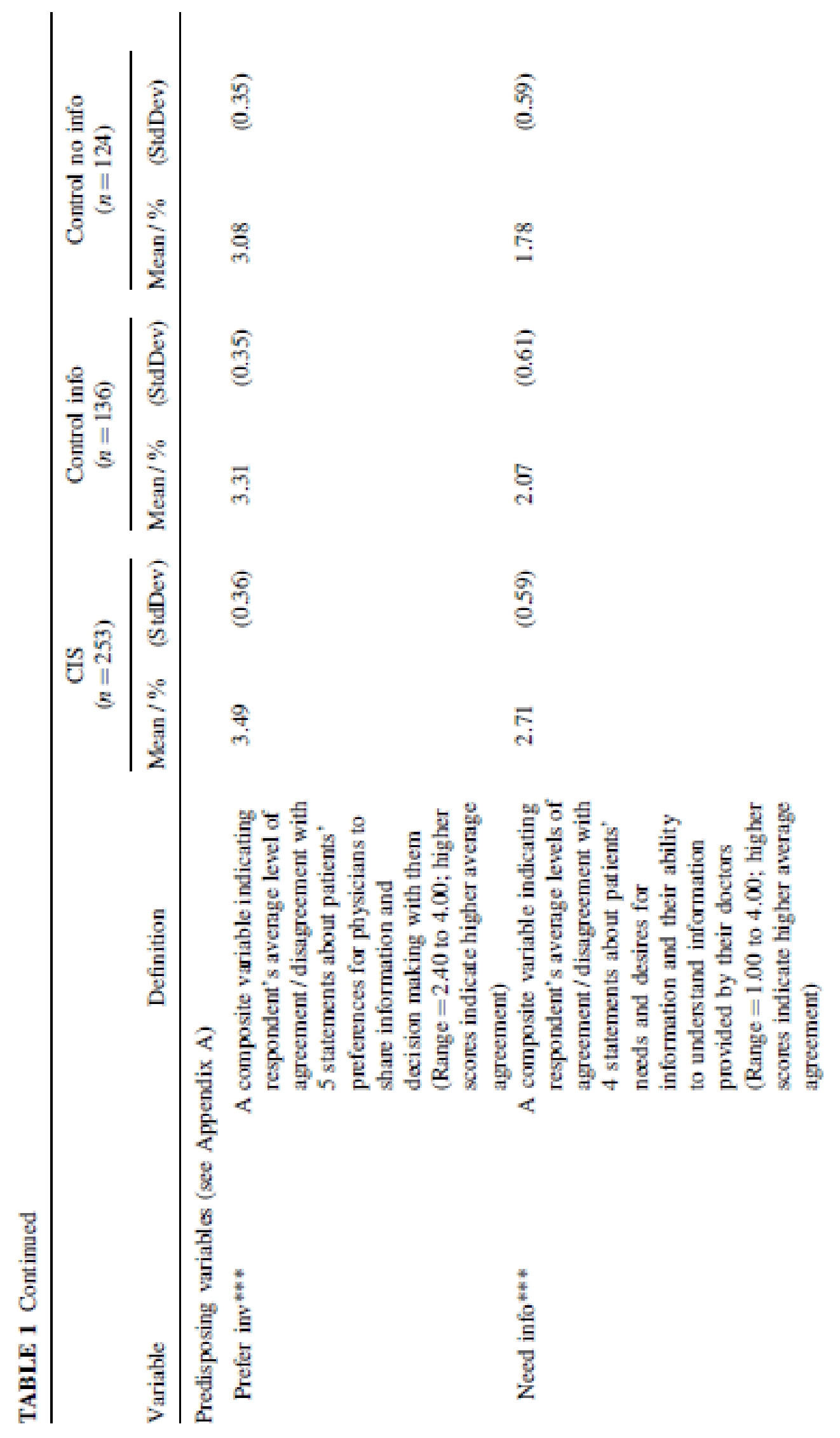


을

$\stackrel{\infty}{\dot{\theta}}$

ํㅜㅇ

$\frac{4}{4} \frac{4}{4}$

f?

$\$$

宇

๑ே

t)

ले

क

ๆे.

$\stackrel{\infty}{=}$

๑ே

$\stackrel{\oplus}{0}$

g.

$\stackrel{8}{\circ}$

กี

भे

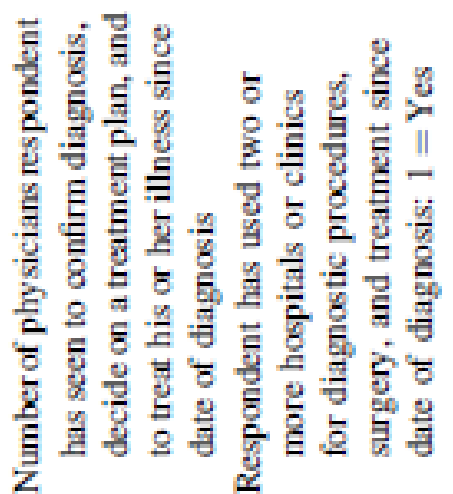

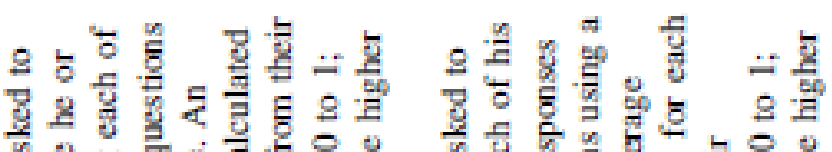

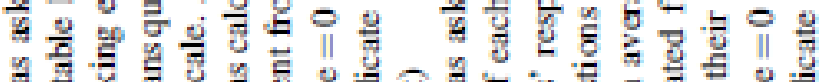

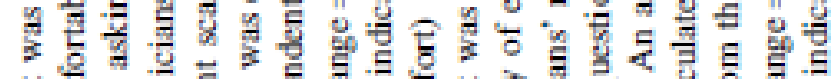

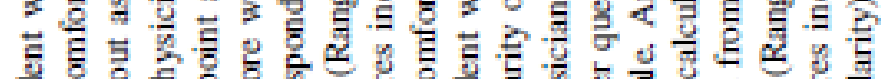

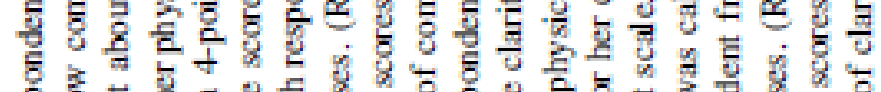

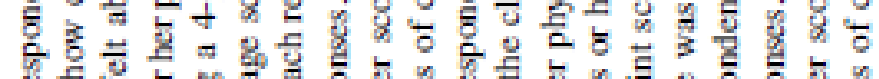

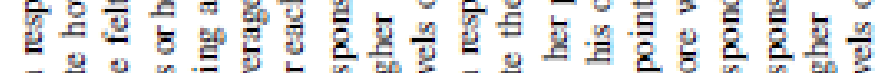

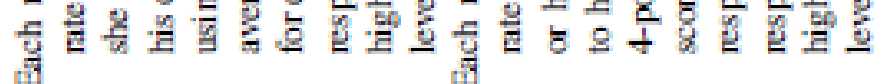
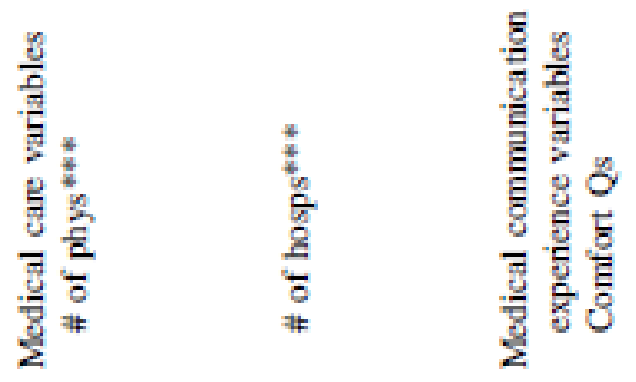

$\frac{6}{0}$
$\frac{5}{6}$
를 


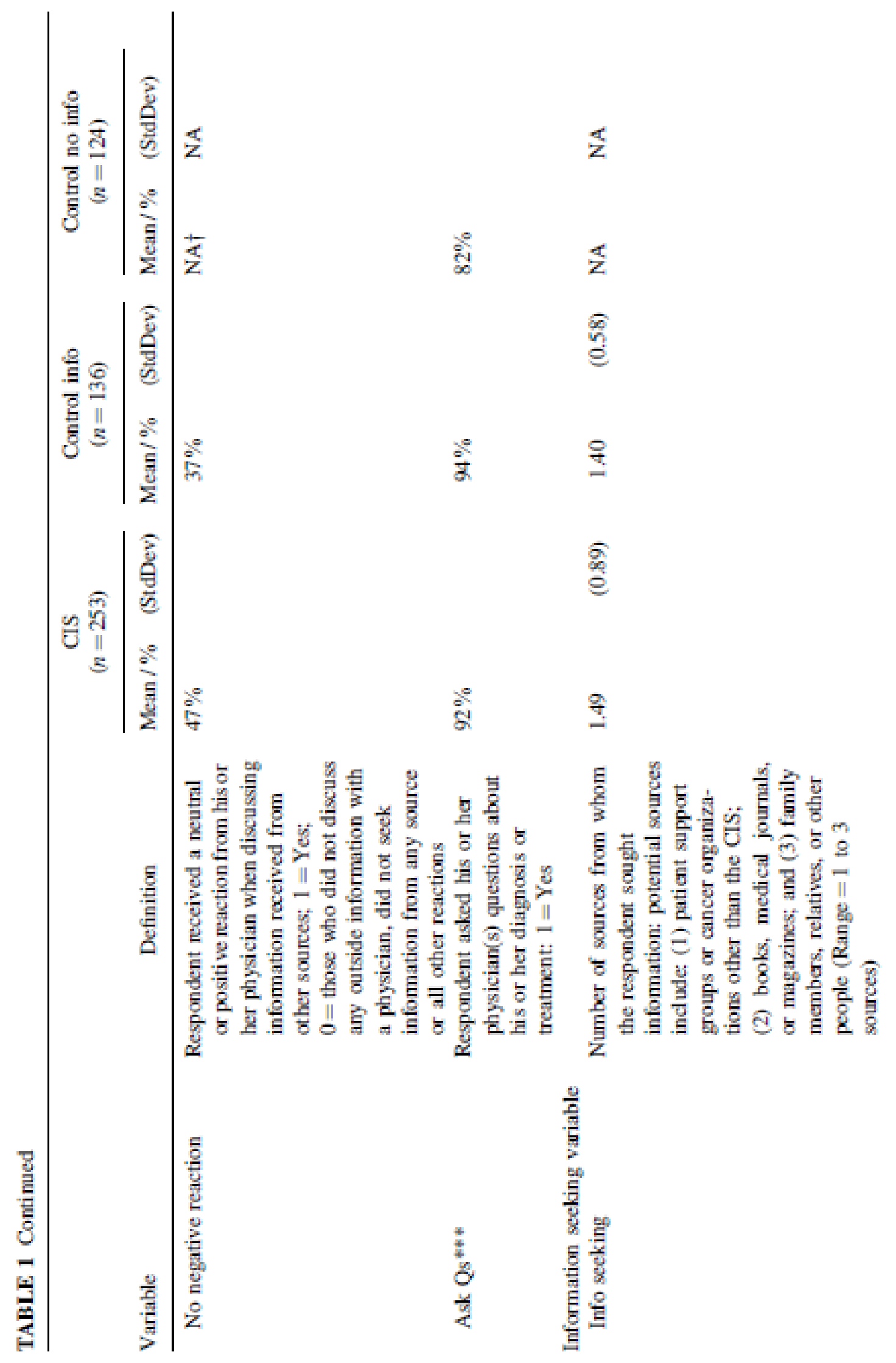




$$
\begin{aligned}
& \text { z } \\
& \text { z } \\
& \stackrel{\leftrightarrow}{\ominus} \\
& \text { के क } \\
& \stackrel{2}{=} \\
& \text { है }
\end{aligned}
$$

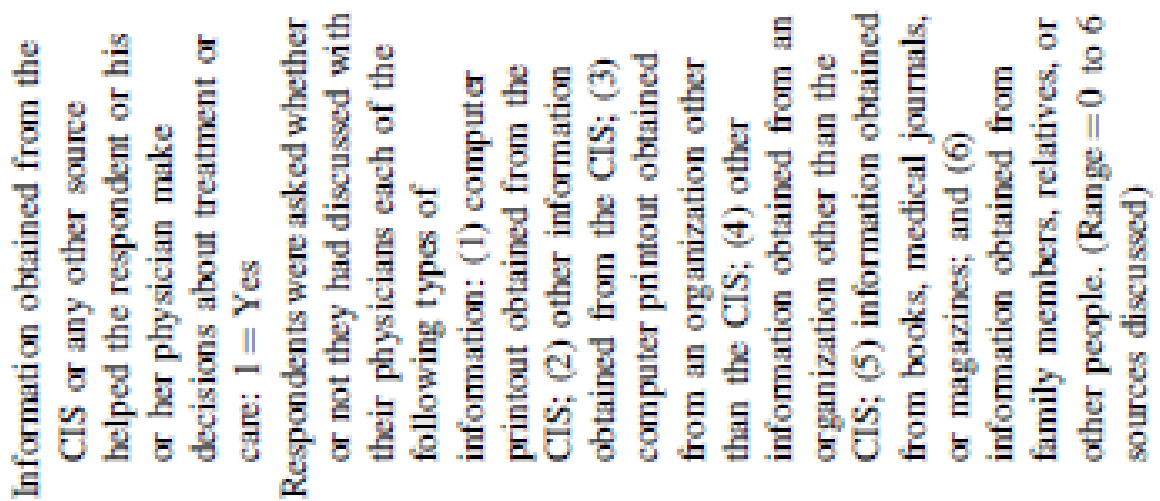

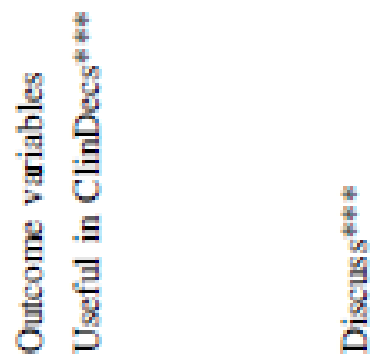




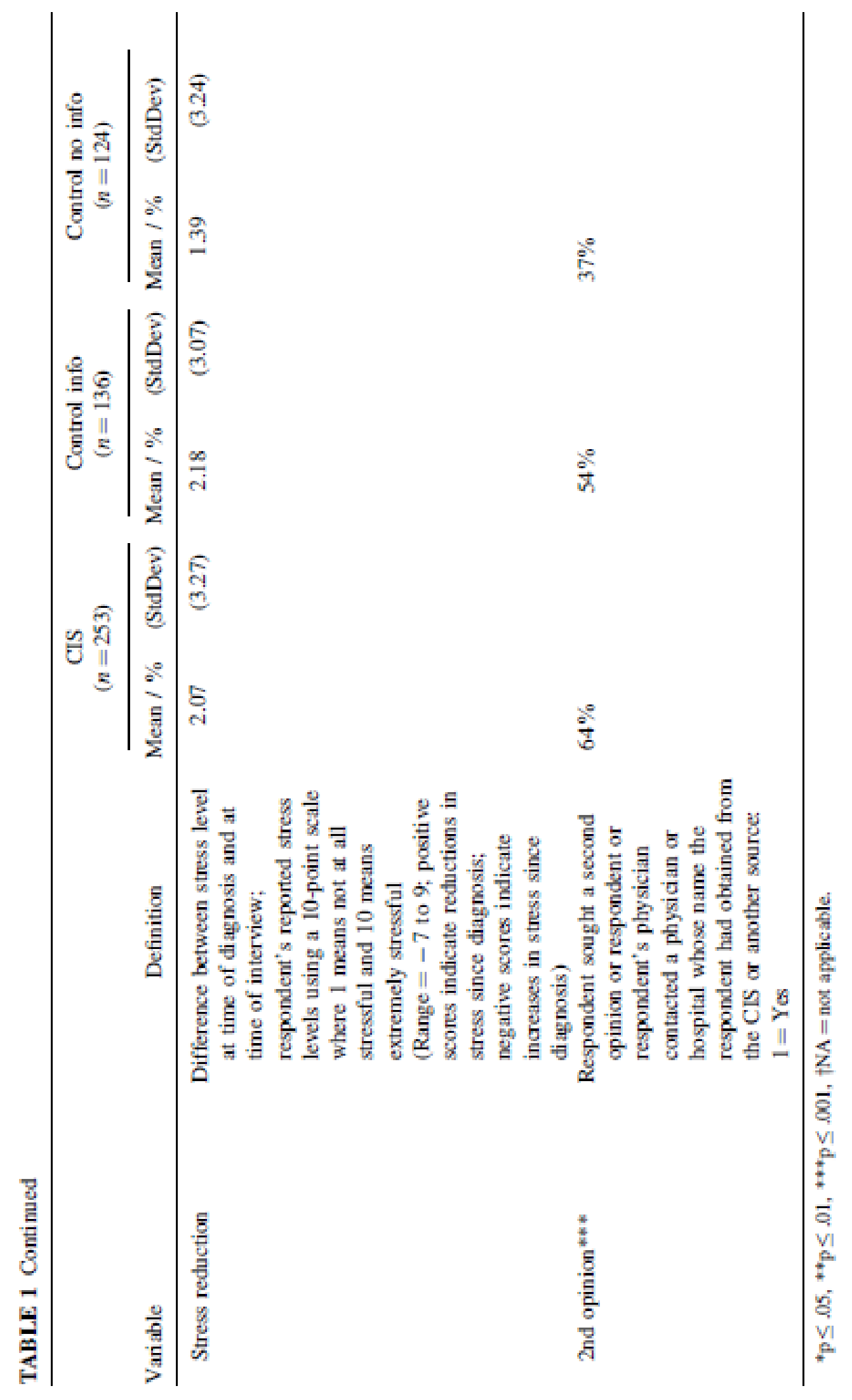


We imputed values for missing data on the number of physicians. Five respondents either did not know how many physicians they had seen or did not respond to this question. In these cases, we substituted the average number of physicians seen by other members of their sample group. "Don't know" or "no answer" responses to the questions about social support, previous knowledge, and clinical decision were recoded into the "No" response category. Three cases were dropped from the analysis because of missing data on age; two cases were dropped because of missing data on gender, and one case was dropped because of missing data on education. As a result, the final samples for data analysis include 253 CIS patients, 136 Control Information patients, and 124 Control No-Information patients.

\section{Estimation}

We used structural equation analysis to test each model separately for each group. This technique includes the calculation of direct, indirect, and total effects. See Triemstra, Van Der Ploeg, Smit, Briet, Ader, and Rosendaal (1998) and Vilhjalmsson (1998) for a concise explanation of this technique, or Bollen (1989) for more detail. We estimated a fully recursive final model with the exception of paths between the enabling and diagnosis factors. This means that we included paths from each variable to each subsequent variable with the two exceptions. The maximum likelihood estimates equal ordinary least squares estimates in a recursive, observed variable model like ours. In turn, an ordinary least squares model converts to a linear probability model with dummy endogenous variables. This allows us to maintain the same estimator throughout the model although the level of measurement varies across the endogenous variables. For previous estimations of models with varying levels of measurement in endogenous variables see Winship and Mare (1983, 1984), Asher (1983) and Land (1969).

We decomposed the effects (direct, indirect, and total) of information seeking and health outcome variables across the three groups. These coefficients are found in Tables $2-4$, along with the adjusted $\mathrm{R}$ square as a measure of equation fit. In parentheses in the text we denote what percentage of the total effect is due to a direct or indirect effect. We tested the significance of the direct and total effects to aid in interpreting the results. Similarly, we calculated standardized effects to help compare the coefficients across the three groups. We graphically present the final trimmed models for each group in Figures $3-5$, including only the significant paths and the standardized coefficients. These diagrams include measures of overall model fit, including chi-square, the adjusted goodnessoffit index (AGFI), and the comparative fit index (CFI). See Triemstra et al. (1998) and Vilhjalmsson (1998) for a brief explanation of these measures, or Bollen (1989) for a more lengthy one. Correlations between the exogenous variables in each model are given in Appendix B. 


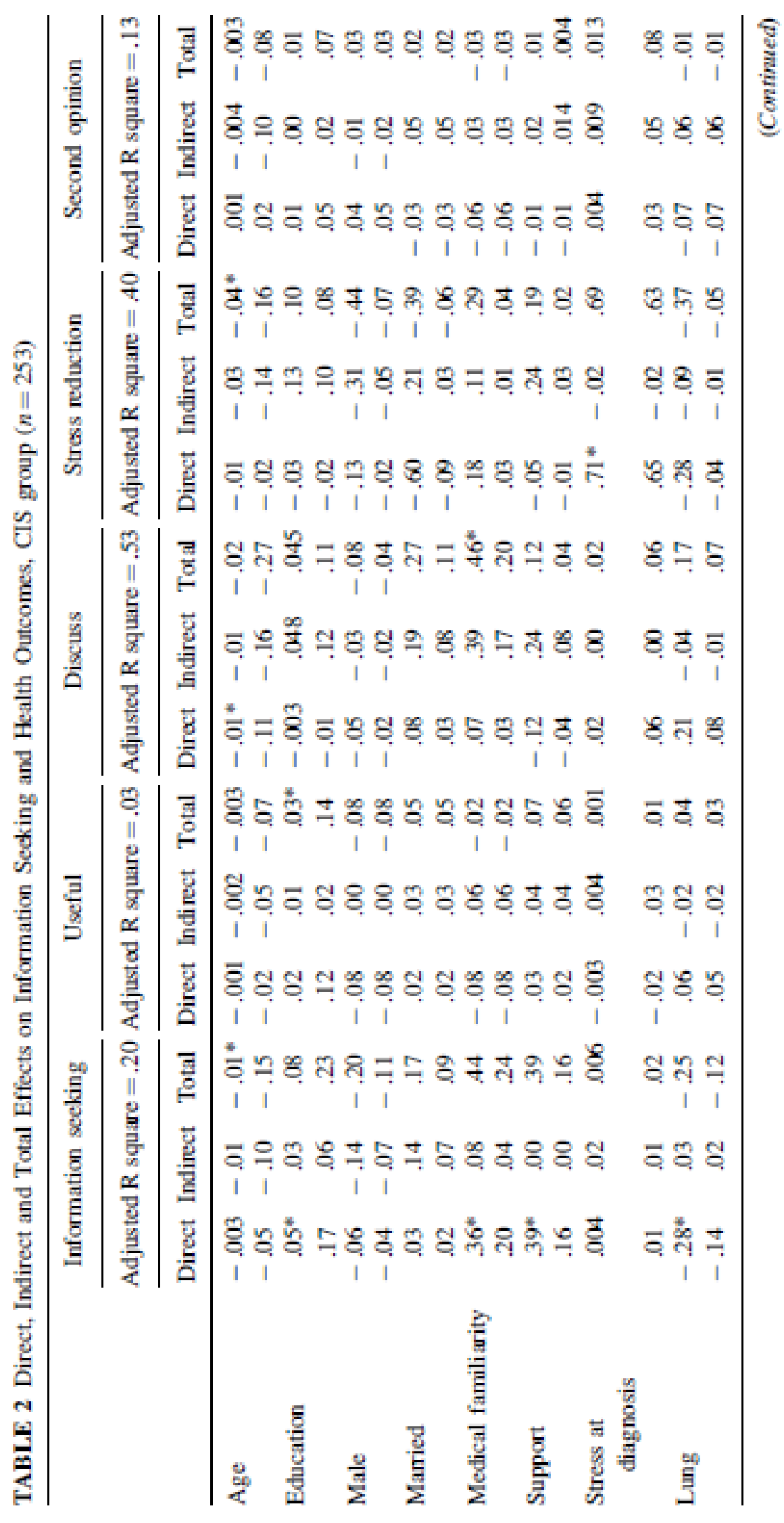




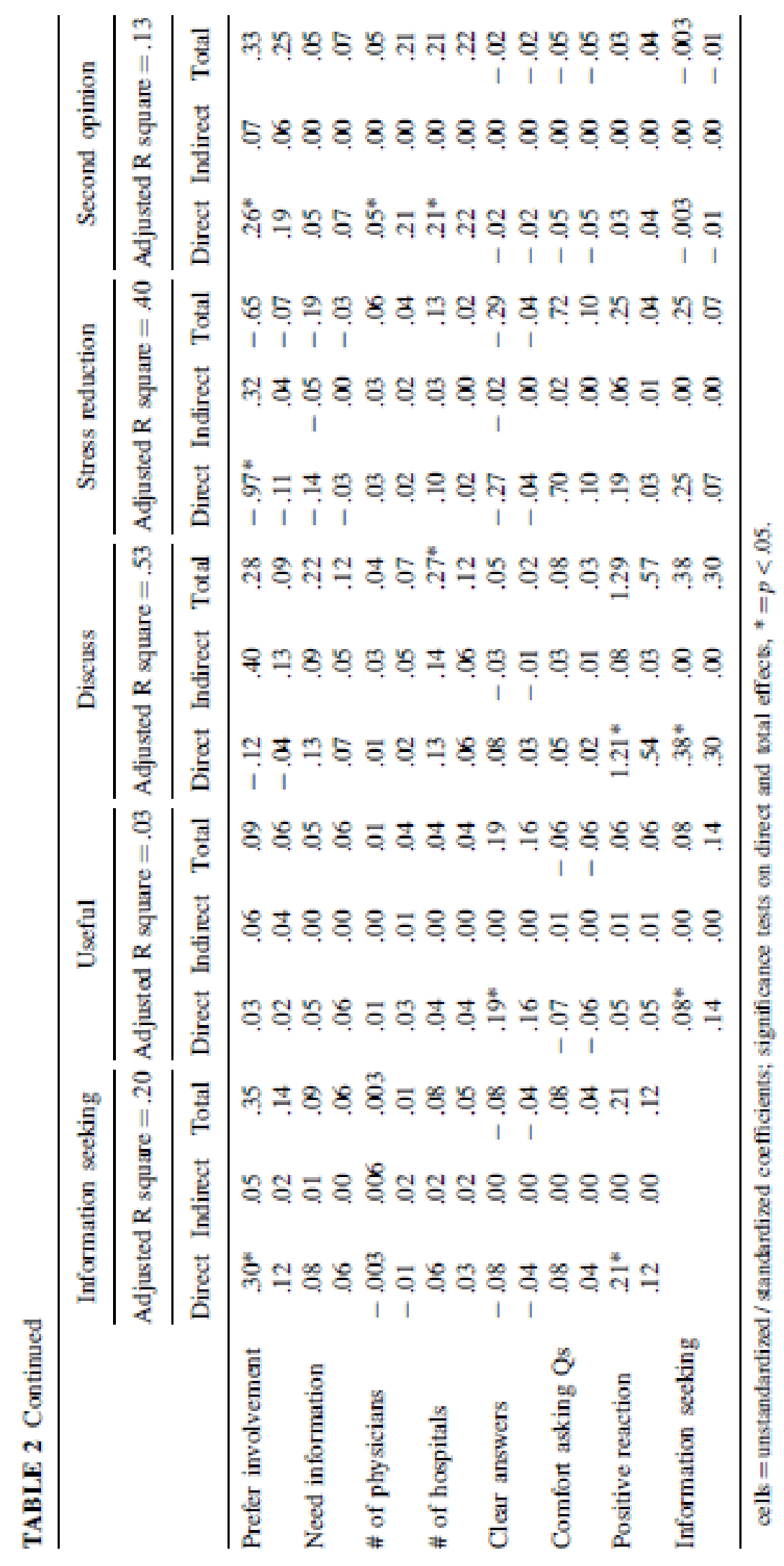




\section{RESULTS}

\section{BIVARIATE RELATIONSHIPS}

The three sample groups differ in many important ways as shown in Table 1. In most comparisons the Control Information group is more similar to the CIS group than to the Control No-Information group. The Control No-Information group is more likely than the other two groups to be older, male, and to have less formal education; they report less social support and less contact with the health care system and they have learned less about cancer from relatives and friends with cancer; they also report less stress at diagnosis than the Control Information and CIS groups; they see fewer physicians, visit fewer hospitals, and are less likely to ask questions of their physicians. Those in the Control No-Information group who did ask questions of their physicians report less clarity in their physicians's responses than the other two groups. Finally, on the two common outcome variables, the Control No-Information group is less likely to seek a second opinion for their diagnosis and they report less change in stress levels between diagnosis and the time of interview. We summarize below the multivariate results focusing on the variables with significant direct and total effects.

\section{PATIENT CHARACTERISTICS}

\section{CIS}

Age is an important variable in the CIS model. It affects six other variables, and, in most cases, higher age has a negative influence. Older $\mathrm{CIS}$ respondents (Figure 3 ) are less likely to (1) receive social support, (2) want physicians to share information and decisions with them, and (3) seek information or discuss information from outside sources with their physicians or receive positive responses when they discuss information from outside sources with their physicians. Age is also negatively related to one outcome variable: discussing information with physicians. As age increases by one year, discussing information with physicians decreases slightly. Fifty percent of this effect is indirect (see Table 2). Male and education are two other important variables for the CIS group. Male has a negative effect on both medical familiarity and receiving social support and a positive effect on lung cancer (i.e., males are more likely to have lung cancer). Education is negatively related to lung cancer and positively related to information seeking. About $63 \%$ of the effect of education on information seeking is direct.

\section{Control Information}

Age is the most important patient characteristic for this group, and, again, the majority of relationships are negative (Figure 4). Age is negatively related to seeing an oncologist, receiving social support, and needing information. Age is positively related to asking physician questions and stress reduction. Of interest to note, age has a direct positive relationship with stress reduction but a negative indirect relationship through receiving social support, number of physicians, and seeing an oncologist (Figure 4). Education is also important. It is positively related to preferring involvement and negatively related to number of hospitals and needing information. Education has an indirect effect on four outcome variables. 


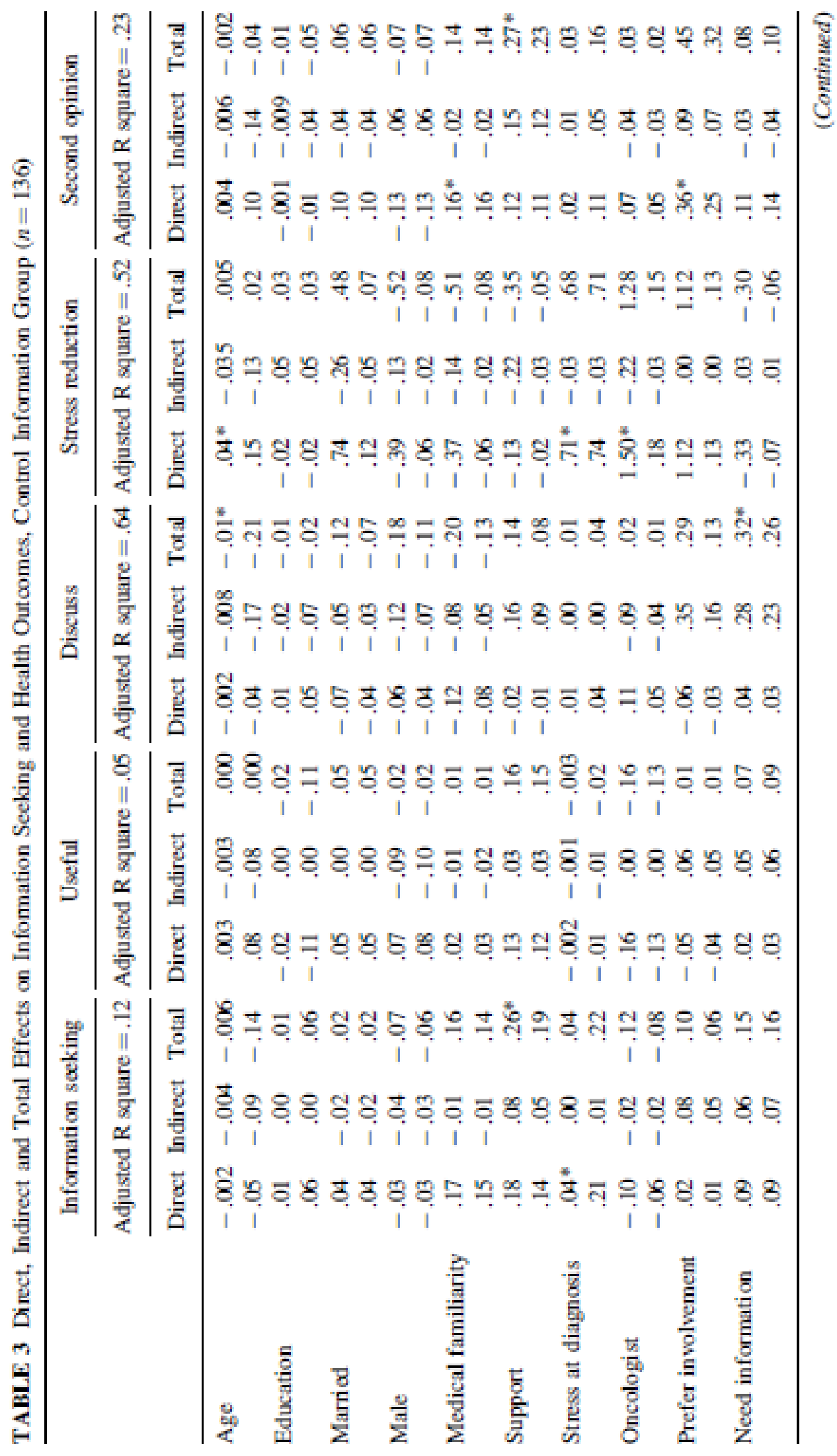




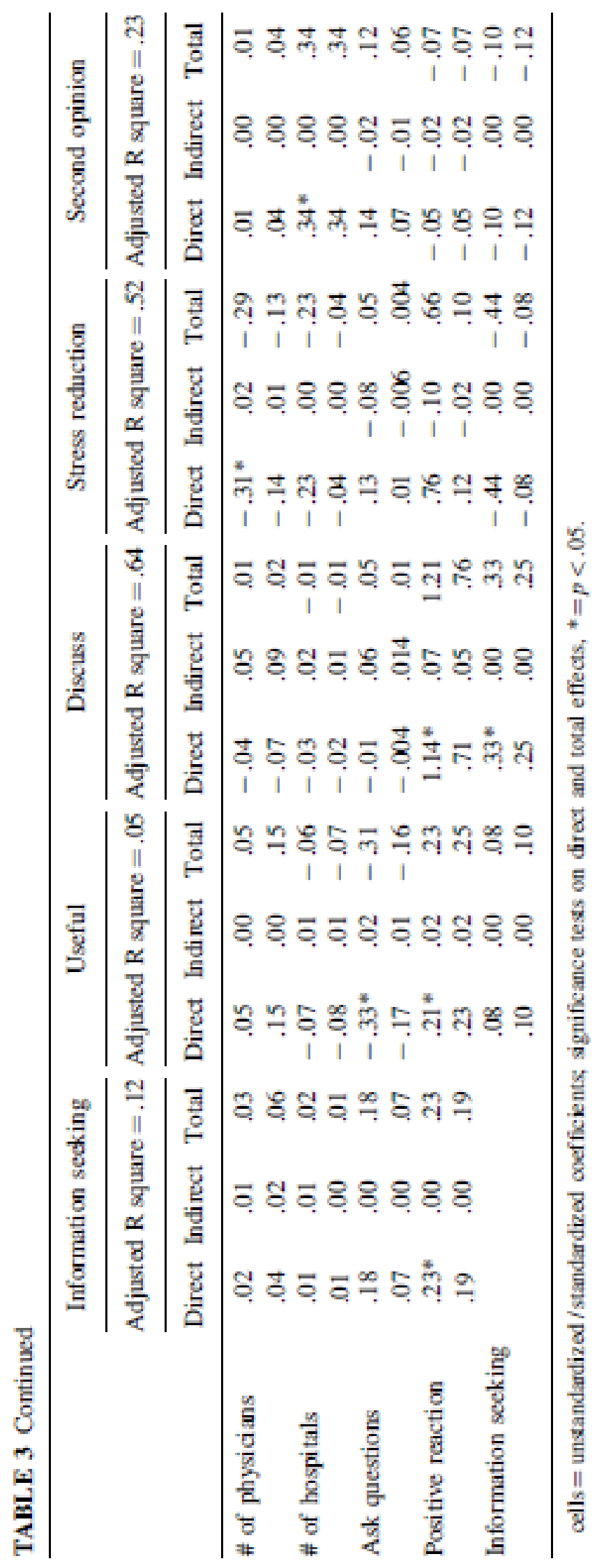




\section{Control No-Information}

As with the other two groups, age is an important variable. Older age shows less stress at diagnosis and number of physicians seen and, subsequently, an indirect effect on both outcome variables (Figure 5). Older patients see fewer physicians and thus are less likely to obtain a second opinion. Marital status has no effect on getting a second opinion but an indirect effect on stress reduction through previous knowledge and needing information. Married patients are less likely to have previous knowledge of cancer due to a friend or relative being diagnosed, and those with no previous knowledge are more likely to report positive changes in stress reduction (Table 4). Married patients are also more likely to need information which leads to a stress increase.

TABLE 4 Direct, Indirect and Total Effects on Health Outcomes, Control No Information Group $(n=124)$

\begin{tabular}{|c|c|c|c|c|c|c|}
\hline & \multicolumn{3}{|c|}{$\begin{array}{l}\text { Stress reduction } \\
\text { adjusted } \mathrm{R} \text { square }=.50\end{array}$} & \multicolumn{3}{|c|}{$\begin{array}{c}\text { Second opinion } \\
\text { adjusted } \mathrm{R} \text { square }=.20\end{array}$} \\
\hline & Direct & Indirect & Total & Direct & Indirect & Total \\
\hline \multirow[t]{2}{*}{ Age } & -.02 & -.07 & $-.09^{*}$ & .002 & -.005 & -.003 \\
\hline & -.07 & -.24 & -.31 & .06 & -.13 & -.07 \\
\hline \multirow[t]{2}{*}{ Education } & -.11 & -.03 & -.14 & -.004 & .014 & .01 \\
\hline & -.09 & -.03 & -.12 & -.02 & .08 & .06 \\
\hline \multirow[t]{2}{*}{ Married } & -.03 & -.34 & -.37 & -.01 & .03 & .02 \\
\hline & -.004 & -.056 & -.06 & -.01 & .03 & .02 \\
\hline \multirow[t]{2}{*}{ Previous knowledge } & $-.61 *$ & .19 & -.42 & -.06 & -.01 & -.07 \\
\hline & -.18 & .05 & -.13 & -.11 & -.02 & -.13 \\
\hline \multirow[t]{2}{*}{ Support } & .29 & -.18 & .11 & .09 & .06 & .15 \\
\hline & .05 & -.03 & .02 & .09 & .07 & .16 \\
\hline \multirow[t]{2}{*}{ Stress at diagnosis } & $.71^{*}$ & -.01 & .70 & .02 & -.01 & .01 \\
\hline & .69 & -.01 & .68 & .10 & -.04 & .06 \\
\hline \multirow[t]{2}{*}{ Colon } & .20 & .17 & .37 & .04 & -.12 & -.08 \\
\hline & .03 & .02 & .05 & .04 & -.12 & -.08 \\
\hline \multirow[t]{2}{*}{ Prefer inwolvement } & -.56 & -.14 & -.70 & $.29^{*}$ & .07 & 36 \\
\hline & -.06 & -.02 & -.08 & .21 & .05 & .26 \\
\hline \multirow[t]{2}{*}{ Need information } & $-.83^{*}$ & -.09 & -.92 & -.14 & .04 & -.10 \\
\hline & -.15 & -.02 & -.17 & -.18 & .06 & -.12 \\
\hline \multirow[t]{2}{*}{ \# of physicians } & -.22 & .00 & -.22 & $.09^{*}$ & .00 & .09 \\
\hline & -.08 & .00 & -.08 & .22 & .00 & .22 \\
\hline \multirow[t]{2}{*}{ \# of hospitals } & -.57 & .00 & -.57 & $.31^{*}$ & .00 & 31 \\
\hline & -.08 & .00 & -.08 & .28 & .00 & .28 \\
\hline
\end{tabular}

cells = unstandardized/standardized coefficients; significance tests on direct and total effects, $*=p<.05$. 


\section{ENABLING}

\section{CIS}

Medical familiarity and receiving social support are important enabling variables for the CIS group. Medical familiarity has an impact on three other variables with a direct positive effect on information seeking and an indirect positive effect on the other four outcome variables. Patients who work for a health care organization or have a relative or close friend in a health related occupation are more likely to seek information. Most of this effect is direct: $82 \%$ (Table 2). Receiving social support also has a positive direct $(100 \%)$ effect on information seeking.

\section{Control Information}

For this group, medical familiarity and receiving social support are also key enabling variables. Medical familiarity has a significant direct effect on getting a second opinion while receiving social support has a significant total effect on both information seeking and getting a second opinion (Table 3).

\section{Control No-Information}

Previous knowledge about cancer has a negative direct and a positive indirect effect (through needing information) on stress reduction. Relative to other patients, those with a seriously ill friend or relative experienced a .42 units increase in stress after diagnosis. About $76 \%$ of the total effect is direct (Table 4). An important finding for this group is that receiving social support is not an important variable. No patient characteristics are related to it and it does not affect any other variables in the model.

\section{DIAGNOSIS}

\section{CIS}

Stress at diagnosis and lung cancer each have a direct effect on one outcome variable. Stress at diagnosis has a direct positive effect on stress reduction. As stress at diagnosis increases, stress reduction also increases (almost all of this effect is direct). In essence, there is a tendency for stress to dissipate over time, especially for younger people and this reduction in stress is not due to any of the measured variables in the model. Surprisingly, stress at diagnosis has no effect on information seeking but lung cancer has a negative direct (90\%) effect on information seeking. Lung cancer patients are least likely to seek information about their illness or treatment.

\section{Control Information}

Stress at diagnosis is a key determinant of four other variables. It has a positive and direct effect on information seeking and stress reduction. Both effects are almost entirely direct. Stress at diagnosis is also a positive determinant of preferring involvement and a negative determinant of receiving no negative reaction from physicians. These latter two 
variables directly affect four outcome variables: information seeking, finding obtained information useful in clinical decision making, discussing information with physicians, and getting a second opinion.

\section{Control No-Information}

Stress at diagnosis has three paths to other variables. It has a positive direct effect on stress reduction and an indirect effect (through preferring involvement and number of physicians) on getting a second opinion. Stress at diagnosis is the most important variable affecting stress reduction. As stress at diagnosis increased one unit, patients report .70 units of stress reduction after diagnosis on a scale of 7 to p 9 (99\%direct effect). The two other variables that affect stress reduction, previous knowledge about cancer and needing information, have a negative impact on stress reduction. Thus, over time, high stress at diagnosis is tempered, but our model does not identify the reasons for this reduction other than an implied time variable.

\section{PREDISPOSING}

\section{CIS}

Prefer involvement is the most important predisposing variable. It has a moderate to large direct effect on three of the five dependent variables-information seeking, stress reduction, and getting a second opinion-and an indirect effect on the other twodiscussing information with physicians and finding obtained information useful in clinical decision making. As preferring involvement increases one unit: a) information seeking increases by .35 units ( $86 \%$ of this effect is direct), b) stress reduction decreases .65 units (75\% direct effect which in effect means stress has increased over time), and c) getting a second opinion increases .33 units on a scale of 0 to 1 (79\% of this effect is direct and $21 \%$ is indirect via number of physicians).

\section{Control Information}

Both predisposing variables are important for this group. Prefer involvement covaries with three other variables and needing information affects two variables. Prefer involvement has a positive direct effect on getting a second opinion (80\% direct effect) and an indirect effect on three of the other outcome variables: information seeking, discussing information with physicians, and finding obtained information useful in clinical decision making. It has no effect, direct or indirect, on stress reduction. Needing information has a positive direct effect on asking physicians questions and receiving no negative physician reactions to questions, and these latter two variables have a direct effect on information seeking, discussing information with physicians, and finding obtained information useful in clinical decision making.

\section{Control No-Information}

Both prefer involvement and needing information have a significant direct effect on an outcome variable. Prefer involvement has a positive effect on getting a second opinion 
(81\% direct effect). Needing information has a negative effect on stress reduction (90\% direct effect). A one unit increase in needing information creates a .92 unit increase in stress over time.

\section{MEDICAL CARE}

\section{CIS}

The number of physicians seen is the most important variable. It covaries with two other medical communication variables and has a positive effect on getting a second opinion (direct effect only). Number of physicians also has an effect on the clarity of physician answers which is directly related to the information being useful in making clinical decisions. Number of hospitals has a positive (direct effect only) effect on getting a second opinion. The total effect of number of hospitals on discussing information with physicians is significant, however, this effect is mediated by later variables in the model.

\section{Control Information}

Both number of physicians and number of hospitals have a significant effect on one outcome variable. Number of physicians has a negative effect on stress reduction. The more physicians seen, the more likely stress increased over time ( $94 \%$ direct effect). Number of hospitals has a positive direct effect (100\%) on getting a second opinion.

\section{Control No-Information}

The number of hospitals visited and number of physicians seen are directly related to getting a second opinion. Patients who visit two or more hospitals and see a large number of physicians are more likely to seek a second opinion.

\section{MEDICAL COMMUNICATION EXPERIENCE}

\section{CIS}

Receiving no negative physician reactions to asking questions about information obtained elsewhere and clear answers from physicians are important variables. Each has at least one significant effect on an outcome variable. No negative reaction from a physician produces: a) a .21 increase in information seeking (direct effect only) and b) a 1.29 increase in discussing information with physicians (94\% direct effect). Clear answers produces a .19 increase in finding obtained information useful in clinical decision making (direct effect only).

\section{Control Information}

Receiving no negative physician reaction is also an important variable for this group. It produces: a) a .23 increase in information seeking (all direct effect); b) a .23 increase in finding obtained information useful in clinical decision making (91\% direct effect); and c) a 1.21 increase in discussing information with physicians ( $94 \%$ direct effect). Asking 
questions of his or her physician about diagnosis or treatment has a negative effect on whether the information was useful in making decisions about treatment or care.

Apparently these respondents asked questions to become informed rather than to participate in making clinical decisions.

\section{Control No-Information}

There are no medical communication variables in the model for this group. There was not enough variation to include them.

\section{INFORMATION SEEKING}

\section{CIS}

Information seeking is an important determinant of two outcome variables. It has a positive relationship with discussing information with physicians and finding obtained information useful in clinical decision making. This group of respondents sought nonphysician sources of information about the disease and treatment, quite possibly to discuss it with their physicians and to participate in clinical decisions. Unexpectedly, there is no relationship between information seeking and getting a second opinion or stress reduction.

\section{Control Information}

Information seeking is related to only one outcome variable, discussing information with physicians, and that relationship is positive. We will suggest an explanation for this shortly.

\section{Control No-Information}

None of the patients in this group sought information about their illness from sources other than their physician.

\section{DISCUSSION AND CONCLUSION}

Our study clearly identifies three groups of patients with different information seeking behaviors. Overall, the demographic and sociopsychological characteristics that distinguish the two groups of patients who sought information from those who did not are consistent with the literature. Age, stress at diagnosis, and preferring involvement had similar impacts on outcome variables in all three groups. Typically, age is negatively related to other variables. In general, older patients are less likely to want involvement and are less proactive. In terms of the outcome variables, older patients in all three groups experienced less stress reduction over time and were less likely to seek a second opinion. Asecond variable - stress at diagnosis_-had a significant positive and direct effect on stress reduction for all three groups. In addition, for the two control groups, stress at diagnosis is 
positively related to preferring involvement, which in turn, is directly and indirectly related to a number of outcome variables for all three groups. Finally, for all three groups there is a positive direct relationship between preferring involvement and number of hospitals used and seeking a second opinion. Patients who want to be involved are more likely to seek a second opinion.

We also found important differences between the sample groups in our study. The CIS group has the highest level of education and reports the highest levels of stress at diagnosis. Most of the CIS patients have social support and familiarity with the medical system and they want their physicians to share information and decision making with them. They feel comfortable asking their physicians questions, they receive clear answers to their questions, and receive neutral or positive reactions from their physicians when they mention information obtained from other sources. This may encourage them to seek information from sources other than their physicians, to discuss this information with their physicians, and to participate in making decisions about treatment and care. A high proportion of this group also sought a second opinion.

The second group, the control group that sought information but not from the CIS, has a mean of almost 13 years of education, reports intermediate levels of stress at diagnosis, and a high proportion have social support. These factors encourage a preference for involvement and information seeking which leads to discussing information with physicians, but only $28 \%$ say they used this information to help make decisions about treatment or care. It appears this group wants to be informed about their disease and treatment but does not want to participate in making treatment decisions.

An important difference between these two information-seeking groups may be the nature of the information they seek or receive. An earlier analysis indicated that the CIS group compared to the Control Information group was much more likely to receive treatment options or clinical trial information and referrals to cancer experts (Manfredi, Czaja, Price, et al., 1993). Among the CIS group, 60\% sought information about treatment options, $29 \%$ about clinical trials, and $28 \%$ sought referrals to cancer experts. The corresponding percentages for the Control Information group were $38 \%, 7 \%$, and $7 \%$, respectively. Another complementary explanation for the differences between these groups is that the CIS respondents start with clearer ideas about their information needs or, when they talk with trained health educators, these staff direct them to information that is pertinent to decision making and encourage them to discuss the information with their physicians.

The third group, the control group that did not seek any information about their illness or treatment from sources other than their physician, is the oldest, has the highest proportion of males, and the lowest mean years of education. Members of this group have the lowest level of social support; the least familiarity with the medical system; the least self-reported anxiety about their cancer diagnosis; and the lowest mean scores on preference for involvement, need for information, and the medical communication variables.

They have the least desire to be involved in decision making and are least likely to seek a second opinion. This group's beliefs and behavior are stereotypical of a traditional passive patient role.

Another important difference between the groups is the variables which affect information seeking and its consequences. Five of the six preceding factors in the modelpatient characteristics, enabling factors, diagnosis factors, predisposing factors, and medical communication experience-affect information seeking for the CIS group. The 
members of this group are more likely than members of the other information-seeking group to use the information they obtain. The CIS group is more likely to discuss information they obtain from outside sources with their physicians and more of them use that information in making clinical decisions. For the Control Information group, information seeking is influenced by only two factors, diagnosis and medical communication experience, and, in turn, it affects only discussing information with physicians.

Overall, our findings mirror previous findings that the desire for information and the desire for involvement in medical care are independent factors (Rees \& Bath, 2001; Leydon et al., 2000; Sutherland, Llewellyn-Thomas, Lockwood, Tritchler, \& Till, 1989; Ende et al., 1989). As many studies have shown (Echlin \& Rees, 2002; Elf \& Wikblad, 2001; Rees \& Bath, 2001; Carlsson, 2000; Nair et al., 2000; van der Molen, 1999; Muha et al., 1998; Woolf \& Dickens, 1995), we found that while most patients say they want information, not all of them seek information and not all that seek information actually use it to participate in medical decision making. The differences between the three sample groups in our study reflect the beliefs and behaviors of three distinct groups within the wider patient population: (1) patients with a strong desire for both information and involvement in making health care decisions; (2) patients who want information but prefer to delegate most decision-making to their physicians; and (3) patients who delegate information-gathering and decision making to their physicians.

Positive health behavior outcomes may occur when patients' preferences and expectations are consistent with their physicians' behavior and when the amount of information they receive is consistent with their coping skills. Supporting this interpretation, information seekers in our study who contacted the CIS have the strongest preference for physicians to share information and medical decision making with them; the strongest desire for and ability to understand information; the most positive reactions from their physicians to their seeking of additional information; and seek the most sources of information.

In contrast, information seekers who do not call the CIS want physicians to share and discuss information with them and they seek information from non-physician sources but most do not actively participate in their health management. It appears that they want to be informed about their disease and treatment, but do not feel the need to participate in making treatment decisions. For them, information-seeking may, as Sutherland et al. (1989, p. 262) explain, "satisfy an aspect of psychological autonomy that does not necessarily include participation in decision making." These patients may want information to determine if they are receiving the most appropriate and effective treatment protocols. Ende et al. (1989) refer to this informed authorization as "paternalism with permission."

Finally, patients in our study who do not seek information prefer less information and participation in their health management. They see it as in their best interest to respect the expertise of their physicians and to follow their physicians' recommendations. It may be more important to these patients, as Lerman et al. (1990, p. 32) concluded, "that their doctor listened to their problems, questions, and concerns; informed them about their health problems; and provided them with an opportunity to express their opinions than it is to perceive that they participated in medical decision making."

Not only do the models in our study identify a number of important determinants in the process of seeking information but they also identify areas for future research. One 
concerns levels of stress. For two groups, CIS and Control No-Information, self reported stress levels are reduced over time but, other than stress at diagnosis, none of the observed variables account for this stress reduction. For both of these groups, previous knowledge leads to increased stress rather than a decrease in stress. For the Control NoInformation group, needing information also increases stress over time. This suggests that at least a portion of the patients who do not seek information would like to do so. Perhaps because of their lower education or older age, these patients may be less able to ask questions of their physicians and are less knowledgeable about where else to seek information. For the Control Information group, four variables affect stress reduction: three positively and one negatively. Older age and being diagnosed by an oncologist result in greater stress reduction over time. Once again, however, the most important variable is a high level of stress at diagnosis which is then reduced by time. The models provide little insight into the dynamics of why over time stress is reduced.

Future research is also needed to verify when and how physician reactions act as a catalyst to information seeking. Our data clearly indicate that physicians play a key role in patient information seeking and patient participation in medical care. Our data also suggest that information seeking is an iterative process in which patients ask a physician questions about their diagnosis and treatment, and, based on no negative reactions, seek more information about their disease and treatment alternatives from a variety of sources. We asked patients at what stages in their illness they sought information and from whom, but we did not specifically ask them what role physicians and their reactions played. Research focused on this process would be valuable.

Another area for future research concerns the elderly and their lack of information seeking and desire for involvement. These relationships have been found in other studies (Carlsson, 2000; Woolf \& Dickens, 1995) and a few studies (Haug \& Ory, 1987; Deber, 1994a, 1994b) have suggested explanations about the elderly's beliefs, behaviors, and situational characteristics that need further testing.

In recent years, two trends have greatly increased the need for patient information and participation. First, the choice between some treatment protocols is increasingly less than clear-cut and may require informed choice based on an evaluation of potential risks and benefits. Second, cancer treatment is increasingly provided as an outpatient service, requiring patients to have information about self-treatment and dealing with side effects. Both of these trends will increasingly require more patient information and involvement, regardless of their initial preferences. In fact, a number of studies have shown a positive effect of providing patients with adequate information for dealing with the uncertainties and choices associated with prostate or breast cancer treatment (Davison \& Degner, 1997; Cyran, 2001) or dealing with the side-effects of and self-medications for cancer treatments (McCaughan \& Thompson, 2000). These beneficial effects occurred even when information giving was initiated by providers and disregarded the patient's initial interests or predispositions. Future research should concentrate not only on refining our understanding of the information process discussed in this paper but also on developing optimal strategies for providing needed information to those cancer patients least prepared to receive it.

In conclusion, we believe that physicians need to assess on an individual basis patient preferences for information and participation and meet those needs accordingly. For those patients who desire information and participation, physicians may need to provide opportunities and incentives for them to not only seek information but also 
to use that information to participate in medical decision making. Physicians also need to be aware of those patients who need information but whose communication skills are inadequate to follow up on those needs. For patients who prefer to rely on their physicians expertise and advise, it may be best for physicians to assume a more traditional role.

\section{REFERENCES}

Aday, L. A., \& Andersen, R. M. (1974). A framework for the study of access to medical care. Health Services Research, 9, 208-220.

Aday, L. A., \& Awe, W. C. (1997). Health services utilization models. In Handbook of Health Behavior Research: Vol. I. Determinants of Health Behavior, ed. D. S. Gochman, pp. 153-172. New York: Plenum.

Andersen, R. M. (1995). Revisiting the behavioral model and access to medical care: Does it matter? Journal of Health and Social Behavior, 36, 1-10.

Andersen, R. M., \& Anderson, O. W. (1967). A Decade of Health Services. Chicago: University of Chicago.

Andersen, R. M., Kravits, J., \& Anderson, O. W., Eds. (1975). Equity in Health Services: Empirical Analyses in Social Policy. Boston: Ballinger Publishing.

Asher, H. B. (1983). Causal Modeling. Beverly Hills: Sage.

Beisecker, A. E., \& Beisecker, T. D. (1990). Patient information-seeking behaviors when communicating with doctors. Medical Care, 28, 19-28.

Bollen, K. (1989). Structural Equations with Latent Variables. Wiley and Sons: New York. Buller, M. K., \& Buller, D. B. (1987). Physicians' communication style and patient satisfaction. Journal of Health and Social Behavior, 28, 375-388.

Carlsson, M. (2000). Cancer patients seeking information outside the health care system. Supportive Care in Cancer, 8(6): 453-457.

Coulton, C. J. (1990). Research in patient and family decision making regarding life sustaining and long term care. Social Work in Health Care, 15, 63-78.

Cyran, E. (2001). Physician sex and other factors associated with type of breast cancer surgery in older women. Archives of Surgery, 136(2): 185-191.

Davison, B. J., and Degner, L. F. (1997). Empowerment of men newly diagnosed with prostate cancer. Cancer Nursing, 20(3): 187-196.

Ende, J., Kazis, L., Ash, A., \& Moskowitz, M. A. (1989). Measuring patients' desire for autonomy: Decision making and information-seeking preferences among medical patients. Journal of Medicine, 4, 23-30. 
Green, L. W. (1974). Toward cost-benefit evaluations of health education: Some concepts, methods, and examples. Health Education Monographs, 2(Supplement), 34-64.

Haug, M. R., \& Ory, M. G. (1987). Issues in elderly patient-provider interactions. Research on Aging, 9, 3-41.

Hughes, K. K. (1993). Decision making by patients with breast cancer: The role of information in treatment selection. Oncology Nursing Forum, 20, 623-628.

Johnson, J. D. (1997). Cancer-Related Information Seeking. Cresskill, NJ: Hampton Press. Johnson, J. D., and Meischke, H. (1993a). Cancer-related channel selection: An extension for a sample of women who have had a mammogram. Women and Health, 20(2): 31-44.

Johnson, J. D., and Meischke, H. (1993b). Differences in the evaluations of communication sources by women who have had a mammogram. Journal of Psychosocial Oncology, 11(1): 83101.

Johnson, J. D., Meischke, H., Grau, J., \& Johnson, S. H. (1992). Cancer-related channel selection. Health Communication, 4, 183-196.

Land, K. (1969). Principles of path analysis. In Sociological Methodology, ed. E. F. Borgatta, pp. 3-37. San Francisco: Jossey-Bass.

Larsson, U. S., Svardsudd, K., Wedel, H., \& Saljo, R. (1989). Patient involvement in decisionmaking in surgical and orthopaedic practice: The project perioperative risk. Social Science and

Medicine, 28, 829-835.

Lavery, J. F., and Clarke, V. A. (1996). Causal attributions, coping strategies, and adjustment to breast cancer. Cancer Nursing, 19(1): 20-28.

Lerman, C. E., Brody, D. S., Caputo, G. C., Smith, D. G., Lazaro, C. G. \& Wolfson, H. G. (1990). Patients' perceived involvement in care scale: Relationship to attitudes about illness and medical care. Journal of General Internal Medicine, 5, 29-33.

Lewis, M., Pearson, V., Corcoran-Perry, S., \& Narayan, S. (1997). Decision making by elderly patients with cancer and their caregivers. Cancer Nursing: 20(6): 389-397.

Leydon, G., Boulton, M., Moynihan, C., Jones, A., Mossman, J., Boudioni, M., \& McPherson, K. (2000). Cancer patients' information needs and information seeking behaviour: In depth interview study. British Medical Journal, 320, 909-913.

Luker, K., Beaver, K, Leinster, S. J., Owens, R., \& Glynn, B. (1996). Information needs and sources of information for women with breast cancer: A follow-up study. Journal of Advanced Nursing, 23(3): 4887-4895.

Manfredi, C., Czaja, R., Buis, M., \& Derk, D. (1993). Patient use of treatment-related information received from the Cancer Information Service. Cancer, 71, 1326-1337. 
Manfredi, C., Czaja, R., Price, J., Buis, M., \& Janiszweski, R. (1993). Cancer patients' search for information. National Cancer Institute, 14, 93-104.

McCaughan, E., \& Thompson, K. (2000). Information needs of cancer patients receiving chemotherapy at a day-care unit in Northern Ireland. Journal of Clinical Nursing, 9(6): 851-858.

Meischke, H., \& Johnson, J. D. (1995). Women's selection of sources for information on breast cancer detection. Health Values, 19(5): 30-38.

Mills, M., \& Sullivan, K. (1999). The importance of information giving for patients newly diagnosed with cancer: A review of the literature. Journal of Clinical Nursing: 8(6): 631-642.

Muha, C., Smith, K. S., Baum, S., Ter Maat, J., \& Ward, J. A. (1998). The use and selection of sources in information seeking: The Cancer Information Service experience. Journal of Health Communication, 3(Supplement): 109-120.

Nair, M. G., Hickok, J. T., Roscoe, J. A., \& Morrow, G. R. (2000). Sources of information used by patients to learn about chemotherapy side effects. Journal of Cancer Education, 15(1): 1922.

Pennbridge, J., Moya, R., \& Rodrigues, L. (1999). Questionnaire survey of California consumers' use and rating of sources of health care information including the Internet. The Western Journal of Medicine, 171(5-6): 302-305.

Deber, R. B. (1994a) The patient-physician partnership: Changing roles and the desire for information. Canadian Medical Association Journal, 151, 171-176.

Deber, R. B. (1994b). The patient-physician partnership: Decision making, problem solving and the desire to participate. Canadian Medical Association Journal, 151, 423-427.

Degner, L. (1997). Information needs and decisional preferences in women with breast cancer. Journal of the American Medical Association, 277(18): 1485-1492.

Derdiarian, A. K. (1989). Effects of information on recently diagnosed cancer patients' and spouses' satisfaction with care. Cancer Nursing, 12, 285-292.

Echlin, K. N., \& Rees, C. E. (2002). Information needs and information-seeking behaviors of men with prostate cancer and their partners: A review of the literature. Cancer Nursing, 25(1): 35-41.

Elf, M., \& Wikblad, K. (2001). Satisfaction with information and quality of life in patients undergoing chemotherapy for cancer: The role of individual differences in information preference. Cancer Nursing, 24(5): 351-356.

Emanuel, E.J., \& Emanuel, L. L. (1992). Four models of the physician-patient relationship. Journal of the American Medical Association, 267, 2221-2226.

Rees, C., \& Bath, P. (2000). The information needs and source preferences of women with breast cancer and their family members: A review of the literature published between 1988 and 1998. Journal of Advanced Nursing, 31, 833-841. 
Rees, C., \& Bath, P. (2001). Information-seeking behaviors of women with breast cancer. Oncology Nursing Forum, 28, 691-698.

Reiser, S. J. (1993). The era of the patient: Using the experience of illness and shaping the missions of health care. Journal of the American Medical Association, 269, 1012-1017.

Scott, J. (1991). A Social Network Analysis: A Handbook. Newbury Park, CA: Sage.

Shapiro, M. C., Najman, J. M., Chang, A., Keeping, J. D., Morrison, J., \& Western, J. S. (1983). Information control and the exercise of power in obstetrical encounter. Social Science and Medicine, 17, 139-146.

Shye, D., Javetz, R., \& Shuval, J. T. (1990). Patient initiatives and physician-challenging behaviors. The views of Israeli health professionals. Social Science and Medicine, 31, 719-727.

Siminoff, L. A., \& Fetting, J. H. (1991). Factors affecting treatment decisions for a lifethreatening illness: The case of medical treatment of breast cancer. Social Science andMedicine, 32, 813-818.

Sutherland, H. J., Llewellyn-Thomas, H. A., Lockwood, G. A., Tritchler, D. L., \& Till, J. E. (1989). Cancer patients: Their desire for information and participation in treatment decisions. Journal of the Royal Society of Medicine, 82, 260-263.

Thoits, P. A. (1995). Stress, coping, and social support: Where are we? What next? Journal of Health and Social Behavior (Extra Issue), 53-79.

Triemstra, A. H. M., Van Der Ploeg, H. M., Smit, C., Briet, E., Ader, H. J., \& Rosendaal, F. R. (1998). Well-being of haemophilia patients: A model for direct and indirect effects of medical parameters on the physical and psychosocial functioning. Social Science and Medicine, 47, 581-593.

Turk-Charles, S., Meyerowitz, B. E., \& Gatz, M. (1997). Age differences in information-seeking among cancer patients. International Journal of Aging \& Human Development, 45(2), 85-98.

van der Molen, B. (1999). Relating information needs to the cancer experience: Information as a key coping strategy. European Journal of Cancer Care, 8(4): 238-244.

Vilhjalmsson, R. (1998). Direct and indirect effects of chronic physical conditions on depression: A preliminary investigation. Social Science and Medicine, 47, 603-611.

Wiggers, H., Donovan, K., Redman, A., \& Sanson-Fisher, R. (1990). Cancer patient satisfaction with care. Cancer, 66, 610-616.

Wilkinson, G. S., \& Wilson, J. (1983). An evaluation of demographic differences in the utilization of a cancer information service. Social Science and Medicine, 17, 169-175.

Winship, C., \& Mare, R. (1983). Structural equations and path analysis for discrete data. American Journal of Sociology, 89, 54-110.

Winship, C., \& Mare R. (1984). Regression models with ordinal variables. American Sociological Review, 49, 512-525. 
Woolf, L., \& Dickens, C. (1995). Who needs information-the changing trends. European Journal of Cancer, 31(Supplement 6): 292.

\section{APPENDIX A: VARIABLES COMPOSING THE PREFER INVOLVEMENT AND NEED INFORMATION SCALES IN THE PREDISPOSING FACTORS}

Based on a principal components factor analysis on sets of seven and five questions, respectively, respondent's answers to the following statements were averaged to compose the summary measures for the Predisposing Factor.

\section{Prefer Involvement}

1. Doctors should make completely clear to a patient the risks for any treatment or operation.

2. Patients should trust their doctors and do what they say without asking a lot of questions.

3. Patients should always get a second opinion before starting any treatment plan.

4. It is all right for patients to ask their physicians to consult with known cancer experts.

5. It is the patient's responsibility to learn as much as possible about his or her disease and possible treatment options.

Response set: 4=Strongly Agree, 3=Agree, 2=Disagree, 1=Strongly Disagree; reversed for question 2 .

Factor loadings ranged from .62 to .74 , reliability $=.68$.

\section{Need Information}

1. I wanted my doctors to discuss all my treatment options with me.

2. I had difficulty understanding what the doctors told me about the cancer or its treatment.

3. I needed more information about my illness.

4. I needed more information about my treatment.

Response set: 4=Very often, 3=Often, 2=Occasionally, 1=Never; reversed for question 2.

Factor loadings ranged from .57 to .90 , reliability $=.73$. 


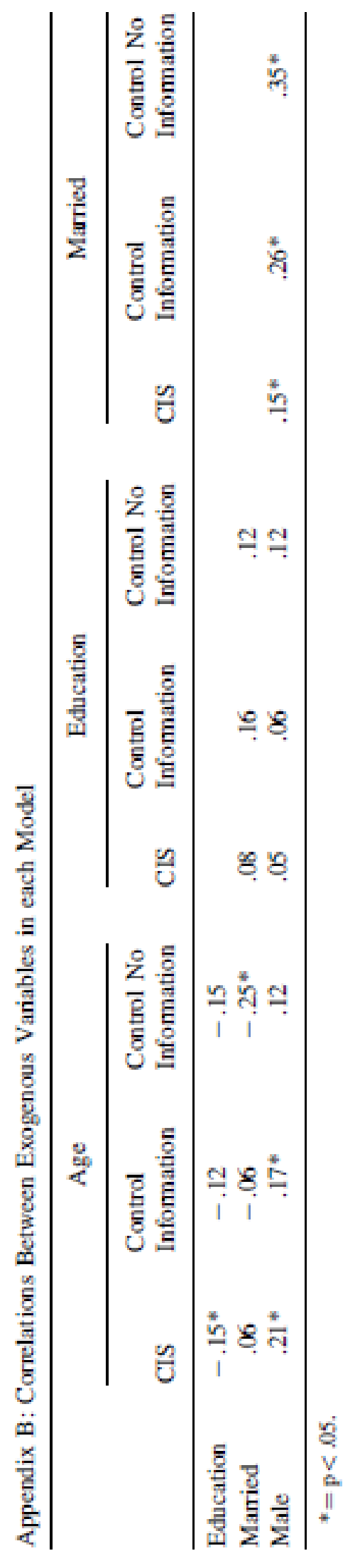

